\title{
Local Land-use Controls and Demographic Outcomes in a Booming Economy
}

\author{
John M. Quigley, Steven Raphael and Larry A. Rosenthal
}

[Paper first received, January 2002; in final form, January 2002]

Summary. The article analyses the link between autarchic land-use policies adopted by local governments in California and the substantial redistribution of its population during the decade of the 1990s. Changes in population growth by racial and ethnic group in California cities are related to measures of the extent to which locally adopted policy favours expansion of the single-family housing stock. Controlling for the initial conditions of housing and labour markets by relying upon census measures for 1990, the paper accounts for the potential endogeneity of contemporaneous land-use policies by relying upon exogenous measures of the 'exclusivity' and 'pro-growth' propensities of the local public sector recorded by a state-wide survey in the early 1990s.

\section{Introduction}

Californians are infamous for describing their state's economy as the sixth-largest in the world, with a GDP exceeding that of Italy, Spain and many other members of the European Union. Besides its size and prodigious rate of economic growth during the 1990s, California is distinguished from other US states and most European economies by its demographic composition and by the unusual character of its local public sector.

First, the demographic composition of the state has always reflected a polyglot of ethnic groups. Internal and international migration have further increased the state's ethnic diversity during the past decade. As reported in the 2000 Census, non-Hispanic Whites are no longer a majority of the state's population and it is unlikely that any single ethnic group will constitute a majority of the population in the near future.

Secondly, the powers of the local public sector in California are almost precisely the mirror image of those exercised in other states and in most European countries. Localities have no discretion at all over local property tax rates or local income tax rates. However, local governments have wide discretion de facto in regulations governing the use of land, urban densities and the development of commercial and residential property.

These land-use controls have indirect fiscal effects to the extent that they affect the incomes of the marginal residents and the aggregate amounts of local tax revenues (at given rates) as well as fee revenue extracted from the development process. By extension, 
these controls indirectly affect the composition of demand for public services, since households of differing socioeconomic status place different demands on the local public sector. Moreover, land-use controls may affect the racial and ethnic composition of marginal residents, given the large betweengroup differences in average socioeconomic status that exist within California and the nation as a whole. ${ }^{1}$

In this paper, we assess whether intercity differences in local residential land-use policy have shaped the large changes in the geographical distribution of racial and ethnic groups within the state of California over the past decade. To measure interjurisdictional variation in government policy, we construct two measures of the extent to which local policy favours expansion of the single-family detached housing stock. The first measure uses the distribution of single-family detached housing units in 1990 along with the number of residential building permits for single-family units issued by local government between 1990 and 2000. We estimate the extent to which the number of newly issued permits deviates from expectations. Higher values of this measure reflect a local public policy biased towards low-density development-i.e. single-family detached housing. The measure also reflects local policies towards growth in the housing stock. We relate this policy measure, the 'Deviations Index', to analogous estimates of the deviation from expectations in the net population growth of non-Hispanic Whites, non-Hispanic Blacks, non-Hispanic Asians and Hispanics.

Next, we construct a variable measuring the proportion of all new residential building permits that are issued for single-family detached housing. Unlike the previous policy measure, the proportion of permits that are single-family reflects only the local bias towards low-density residential development. We relate this latter measure of local landuse policy, the 'Proportions Index', to the proportion of net population growth accounted for by members of each racial/ethnic group.
Our results indicate that net growth in the non-Hispanic White population is particularly sensitive to these measure of local landuse policy. White population growth, measured by deviations from expectations and the proportional contribution to total net growth, is strongly and positively associated with the Deviations Index and the Proportions Index defined above. For Hispanics and Asians (the two fastest-growing groups in the state), we observe the opposite. Specifically, Hispanic and Asian population growth is weakly related to positive values of the Deviations Index and negatively related to the proportion of new permits devoted to singlefamily detached units. The impact on the population growth of African Americans is less clear. While Black population growth is positively related to the issuance of singlefamily permits, the proportion of net growth that is African American is essentially unrelated to the proportion of permits for singlefamily housing.

Of course, these measures of local landuse choices are not predetermined exogenous variables. Rather, they are endogenous to the economic forces that distribute population changes within metropolitan housing and labour markets. We do, however, have two pre-determined measures of the land-use regulations that had been adopted by local governments in California in the early 1990s. We use these measures as instruments in two-stage least-squares (2SLS) models relating population redistribution during the decade to the number and distribution of building permits issued by California cities. Based on surveys of local officials conducted by Glickfeld and Levine (1995), we characterise the extent to which a municipality is 'pro-growth' as well as the extent to which the municipality's land-use policies are 'exclusionary'. We predict a priori that relatively pro-growth municipalities will issue more permits than expected. However, the composition of residential building permits in pro-growth cities should be skewed towards more intensive land use-i.e. multifamily dwellings. Relatively exclusionary cities should issue fewer permits and have a composition of permits skewed towards 
lower-density single-family housing. While the first-stage relationships between the growth control policy measures and the building permits variables are rather weak, the results from this exercise nevertheless confirm the patterns observed using simpler methods.

\section{Describing the Demographic Changes in California, 1990-2000}

During the 1990s, California experienced exceptionally high population growth as well as large changes in the internal composition of the state population. While the population of the remaining 49 states grew by approximately 10 per cent over the decade, the total population of California increased by nearly 14 per cent. This strong overall growth, however, masks contrasting patterns for subgroups of the state population defined by race and ethnicity. Moreover, there are clear spatial patterns in net population movements over the decade.

Table 1 presents figures on the 1990 and 1999 populations for five racial/ethnic groups: non-Hispanic Whites, Blacks, Asians, Native Americans, and Hispanics. Despite the large overall increase in state population, the non-Hispanic White population of California declined by over half a million persons. All other racial and ethnic groups experienced net population increases. The largest population increases are observed for Hispanics (nearly 3 million) and Asians (slightly more than 1 million), while the African American and Native American populations grew slightly over this period. The figures in Table 1 indicate that between 1990 and 1999, the non-Hispanic White population declined from the majority, of 57 per cent, to a plurality, of 49 per cent. Nearly all of this 8 percentage point decline is offset by the 5 percentage point increase in the Hispanic population share (from 26 to 31 per cent) and the 2 percentage point increase in the Asian population share (from 10 to 12 per cent).

This change in population and racial composition has been by no means uniformly distributed among towns in the state or in its metropolitan areas. Figures 1-10 illustrate this diversity. The figures present the changes in residences of demographic groups for the municipalities located within the Los Angeles Consolidated Metropolitan Statistical Area (CMSA) during the 1990s for four racial/ethnic groups. ${ }^{2}$ Figure 1 presents the baseline 1990 distribution of total population, while Figure 2 presents the spatial patterns of net population growth during the decade. As can be seen, total population growth is roughly proportional to the 1990 population distribution.

Figures 3 and 4 report the changes in the spatial patterns of the African American population during the decade. The cities gaining population include suburban developments east of Los Angeles along major interstate highways (I-10 and I-15) as well as the communities north of downtown. The cities with positive growth are generally older inner-ring suburban cities of the metropolitan area. In contrast, the cities experiencing net loss in Black population are the historically Black cities located near the metropolitan area centre. Black population loss is geographically concentrated.

The spatial patterns of White population

Table 1. Racial and ethnic composition of California, 1990-99

\begin{tabular}{lrr}
\hline & \multicolumn{2}{c}{ Population (thousands) } \\
\cline { 2 - 3 } & \multicolumn{1}{c}{1990} & 1999 \\
\hline Non-Hispanic White & 17089 & 16526 \\
Black & 2322 & 2487 \\
Asian & 2933 & 4038 \\
Native American & 288 & 314 \\
Hispanic & 7776 & 10460 \\
Total $^{\text {a }}$ & 29950 & 33825 \\
\hline
\end{tabular}

${ }^{a}$ The total population estimates are slightly less than the sum of the figures for the independent racial/ethnic categories listed in the table due to the fact that there is a small amount of overlap between the Hispanic population and the Asian, Native American and Black populations.

Source: Population Estimates Program, Population Division, US Bureau of the Census. 


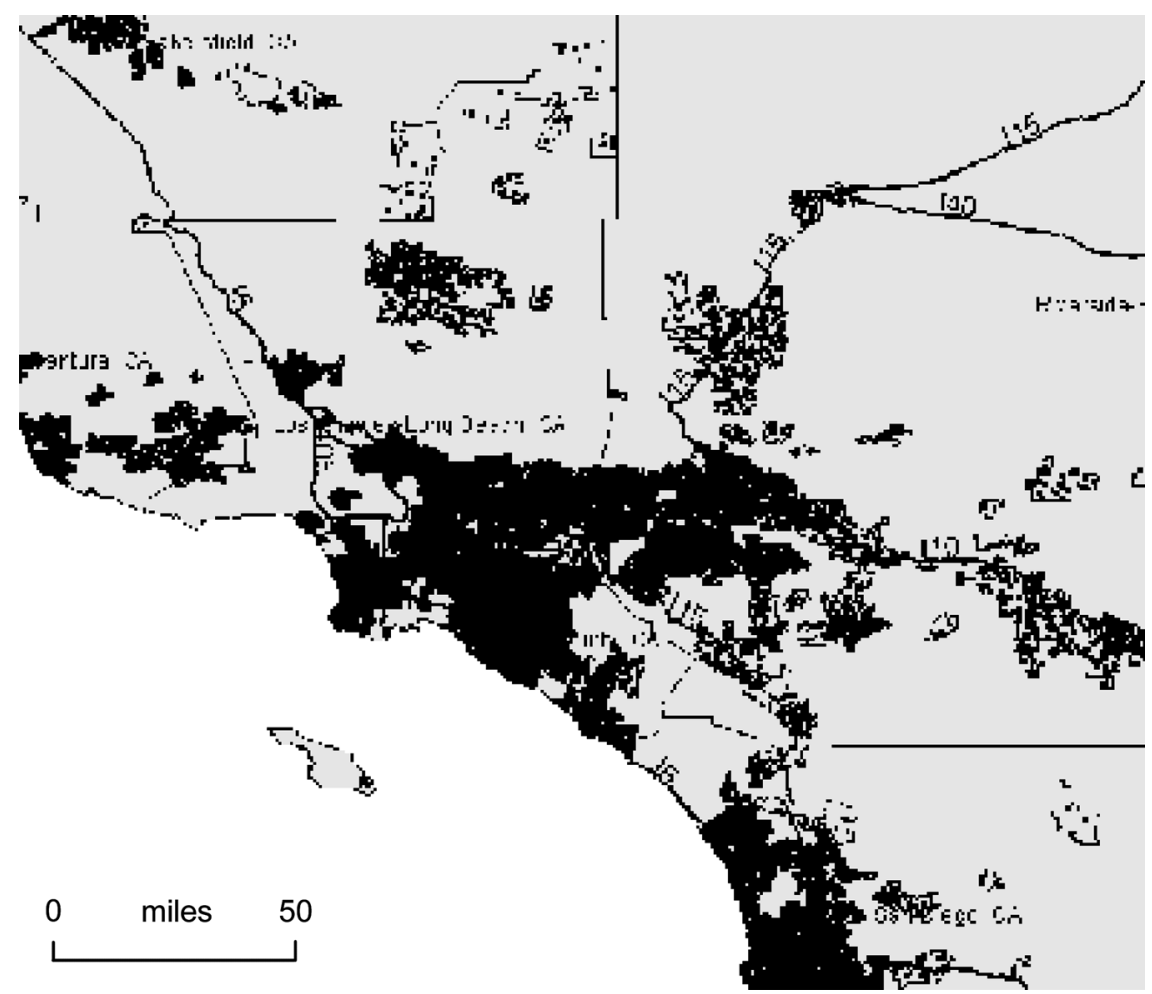

Figure 1. Distribution of total population in the Los Angeles CMSA, 1990. Key: 1 dot represents 500 people.

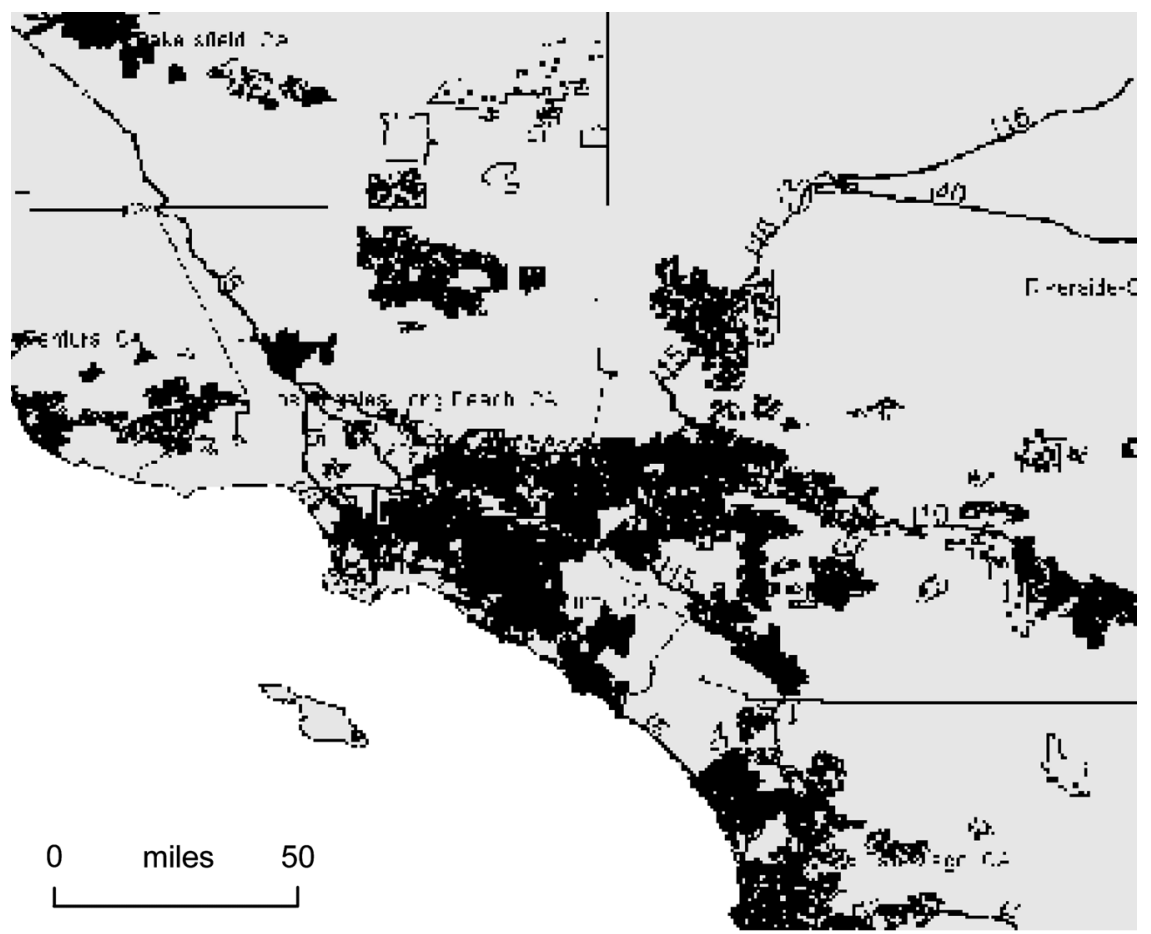

Figure 2. Net growth in total population in the Los Angeles CMSA, 1990-2000. Key: 1 dot represents 100 people. 


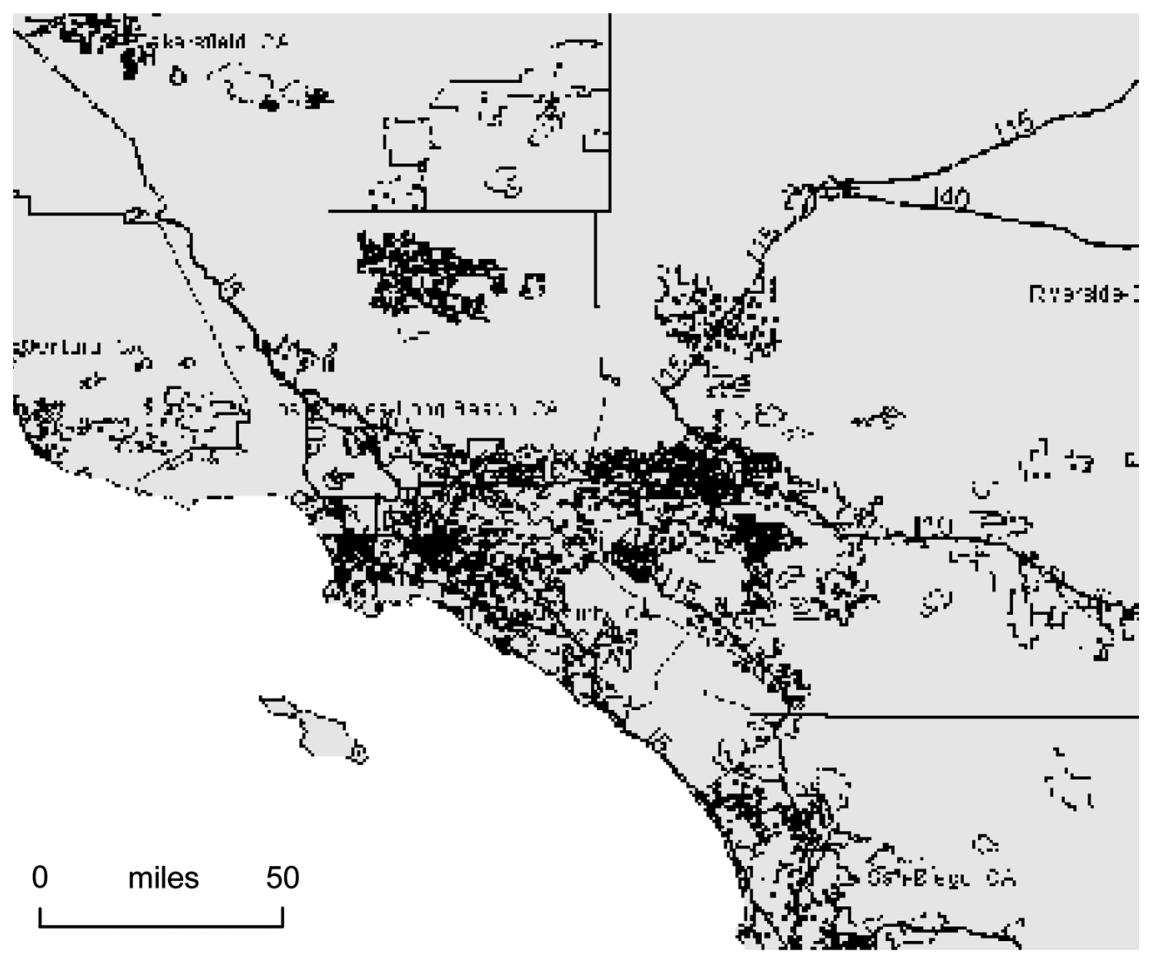

Figure 3. Net growth in the African American population in the Los Angeles CMSA, 1990-2000. Key: 1 dot represents 100 people.

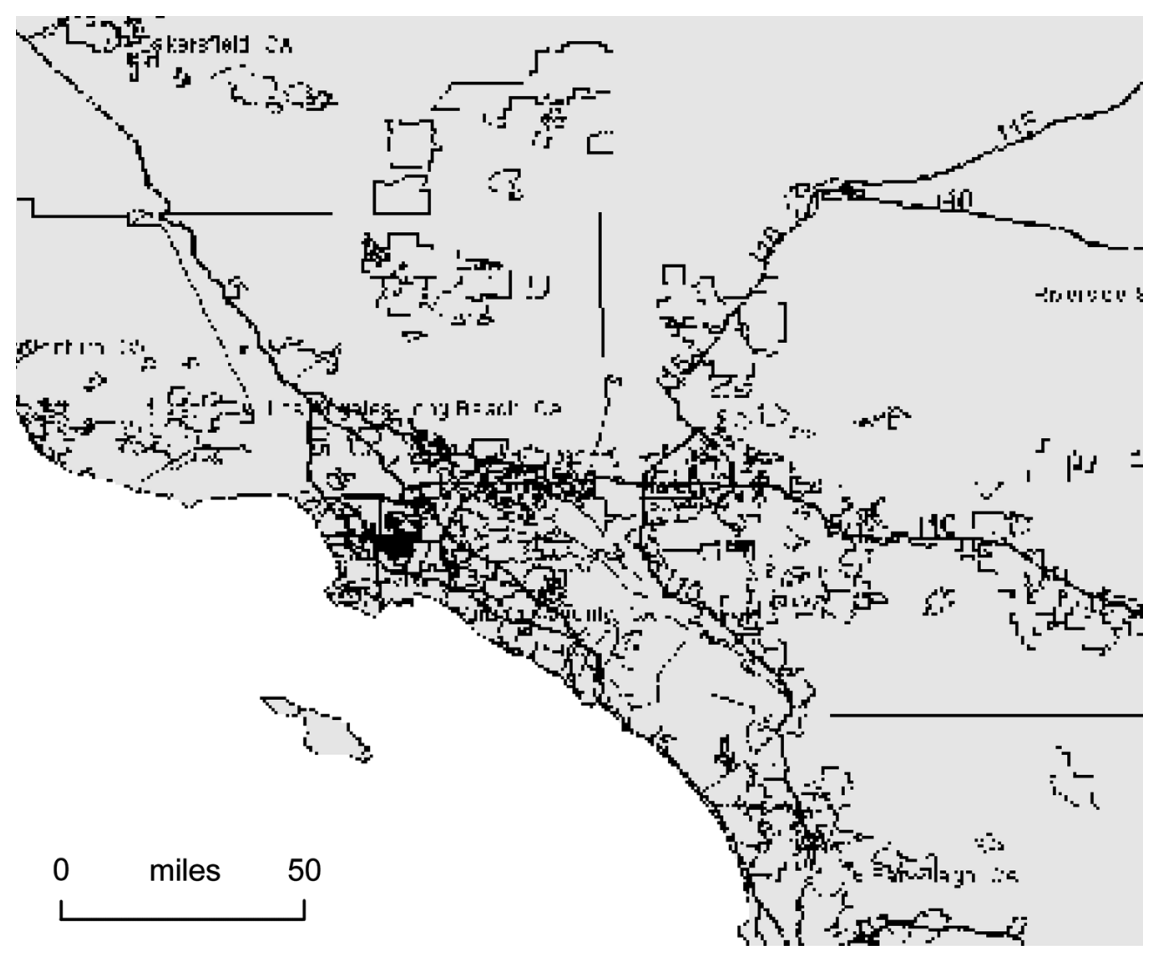

Figure 4. Net loss in the African American population in the Los Angeles CMSA, 1990-2000. Key: 1 dot represents 100 people. 
loss and gain differ considerably from those for the Black population. Figures 5 and 6 illustrate these differences. The areas experiencing net increases in the White population are extremely concentrated and are located in the far suburbs of the CMSA. These areas include relatively new and quickly growing communities along Interstate 15 in Riverside County, as well as relatively exclusive beach cities located midway between the cities of Los Angeles and San Diego. Areas experiencing White population loss, on the other hand, are extremely dispersed and are more numerous. Figure 6 indicates that Whites have left the central municipalities as well as inner-ring suburban cities in droves.

The spatial distributions of Hispanic population change are strikingly different from those for Whites and Blacks. Figure 7 shows that the Hispanic population increased in nearly all cities within the CMSA over the decade and by considerable magnitudes. In contrast, Figure 8 shows that only a few cities (mostly near the central city) experienced modest declines in the Hispanic population. Similarly, Asian population growth (Figure 9) is substantial and geographically dispersed over the CMSA; there is little evidence of any city-level declines (Figure 10).

Patterns similar to those observed in Los Angeles are evident in California's other large urban areas. Whites left central locations (in all but the central city of San Francisco) and White population increases were recorded in a relatively small number of more distant suburban jurisdictions. The Black population declined in central locations, but the population losses were less pronounced. Black population increases were also recorded in a relatively small number of suburban jurisdictions, but not in the same towns that recorded large inflows of Whites. Asian and Hispanic populations increased in virtually all jurisdictions.

Table 2 summarises the spatial concentration of net population losses and gains for all municipalities in the state. The table presents several summary measures of the disparity between the distribution of households by race recorded in 1990 and the changes in population during the decade of the 1990s. The first column presents indices of dissimilarity (see Theil, 1972) between the 1990 population distribution and the distribution of net growth in this population (negative population growth cities are set to zero). The second column presents similar indices measuring the dissimilarity between the 1990 population and the distribution of net population losses (positive growth cities are set to zero). Finally, the last column presents the chi-squared statistic testing the hypothesis that the population change for the relevant group is distributed across jurisdictions in proportion to the initial population levels. Higher values of this statistic indicate greater deviations from random population changes.

The results presented in Table 2 indicate clear differences in the geographical concentrations of population change by race and ethnicity. For instance, the indices of dissimilarity between population and population growth indicate that White population growth was highly concentrated spatially as was Black population growth (though to a lesser extent). For example, 82 per cent of the observed increases in the White population would have to be relocated if the increases were to be distributed in proportion to the distribution of the White population in 1990; the comparable figure for Blacks is 62 per cent. Hispanic and Asian population growth was considerably more dispersed, with dissimilarity values of 33 and 29 respectively. The spatial dissimilarity between initial population and population loss is the mirror image of the dissimilarity indices of population gains. The non-Hispanic White population loss was the most geographically dispersed, with a dissimilarity index of approximately 40 . Black population loss is considerably more spatially concentrated (index value of 61) while Asian and Hispanic population loss is extremely concentrated in a few cities. Both groups have index values in excess of 95 (indicating that 95 per cent of the population loss would have to be redistributed to yield a loss distribution that is proportional to the initial population distribution). 


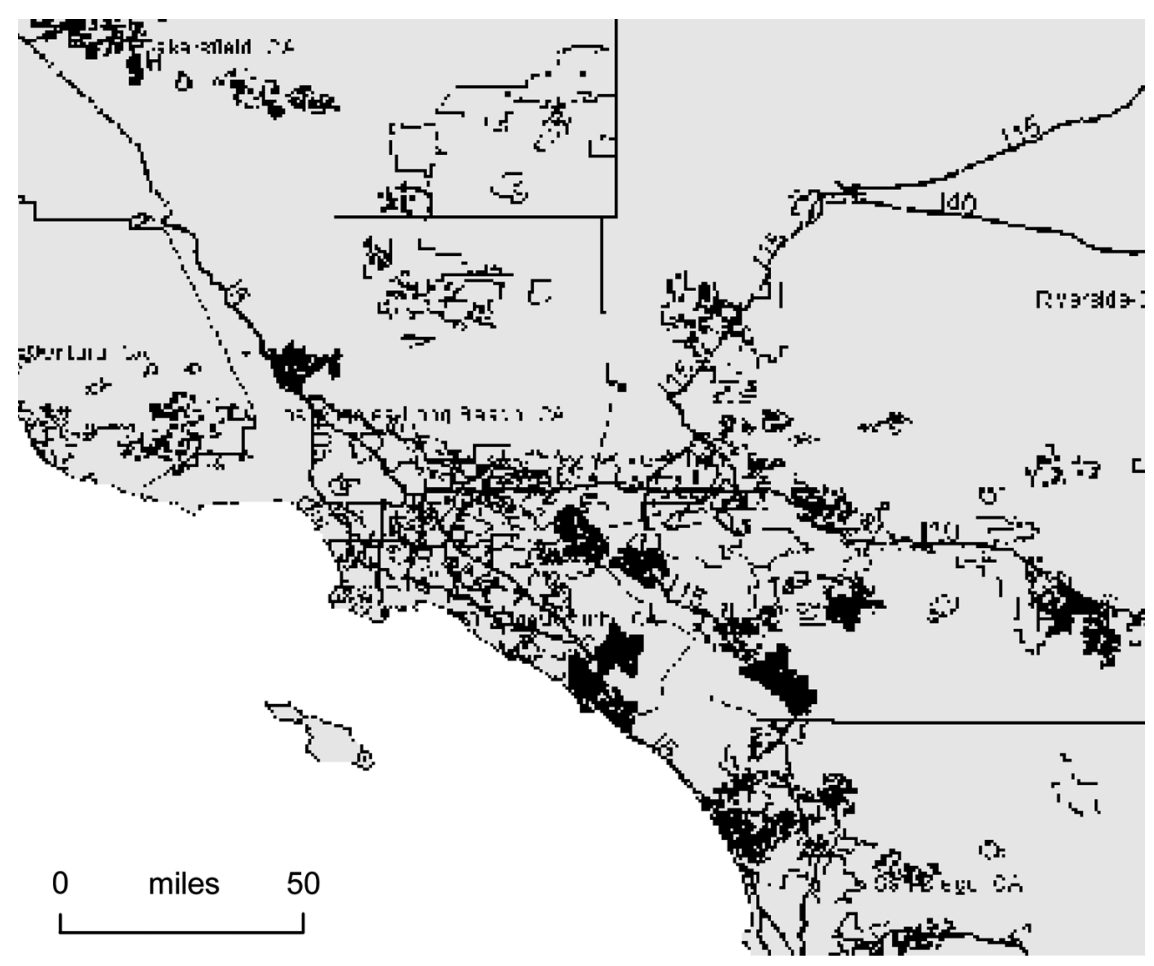

Figure 5. Net growth in the White population in the Los Angeles CMSA, 1990-2000. Key: 1 dot represents 100 people.

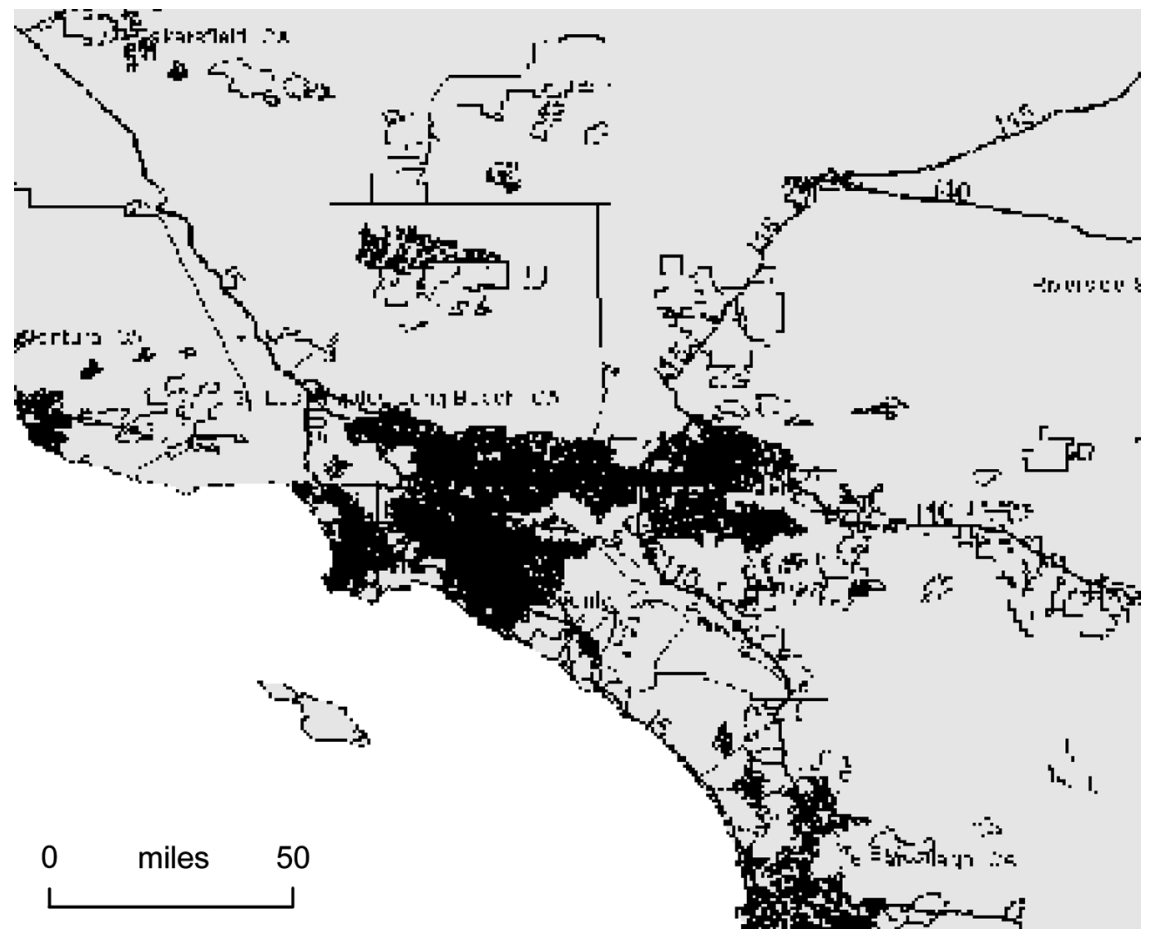

Figure 6. Net loss in the White population in the Los Angeles CMSA, 1990-2000. Key: 1 dot represents 100 people. 


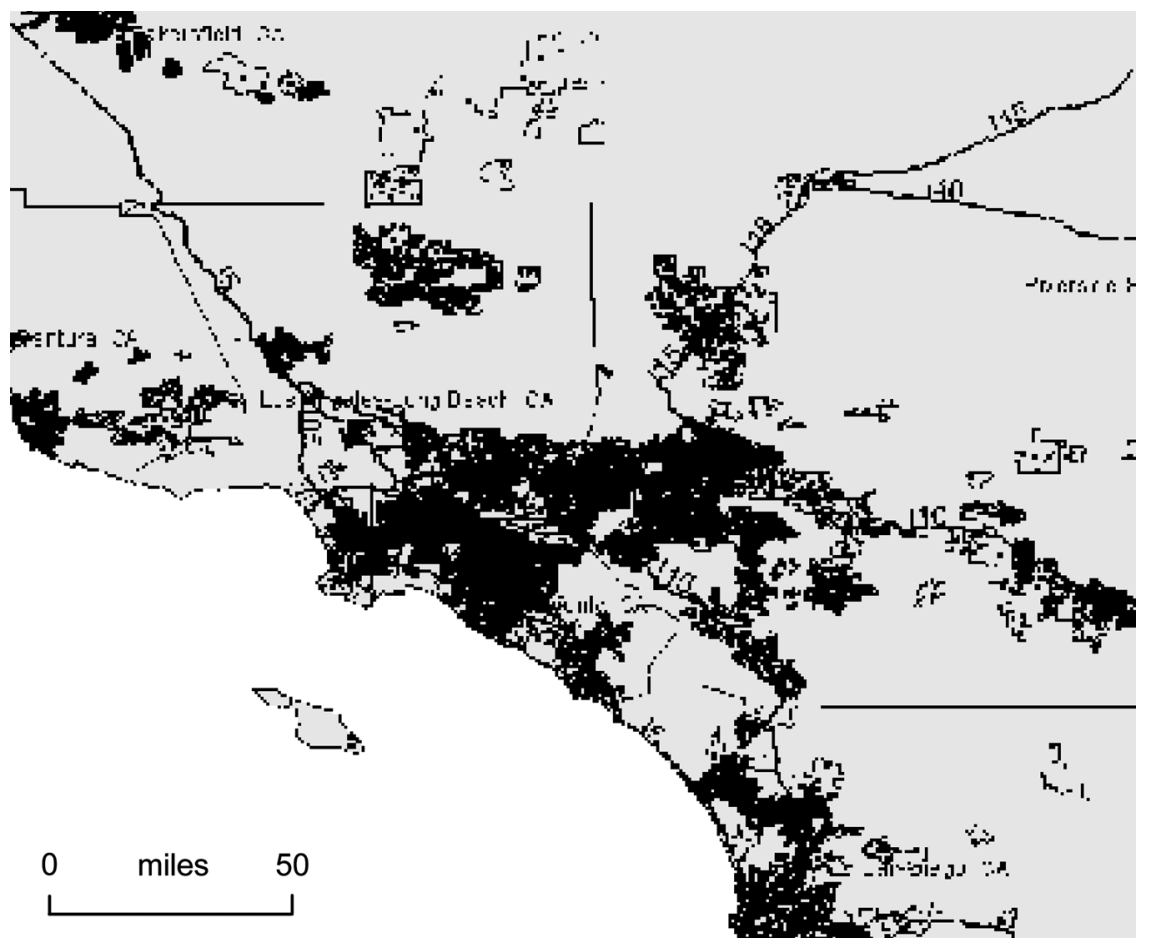

Figure 7. Net growth in the Hispanic population in the Los Angeles CMSA, 1990-2000. Key: 1 dot represents 100 people.

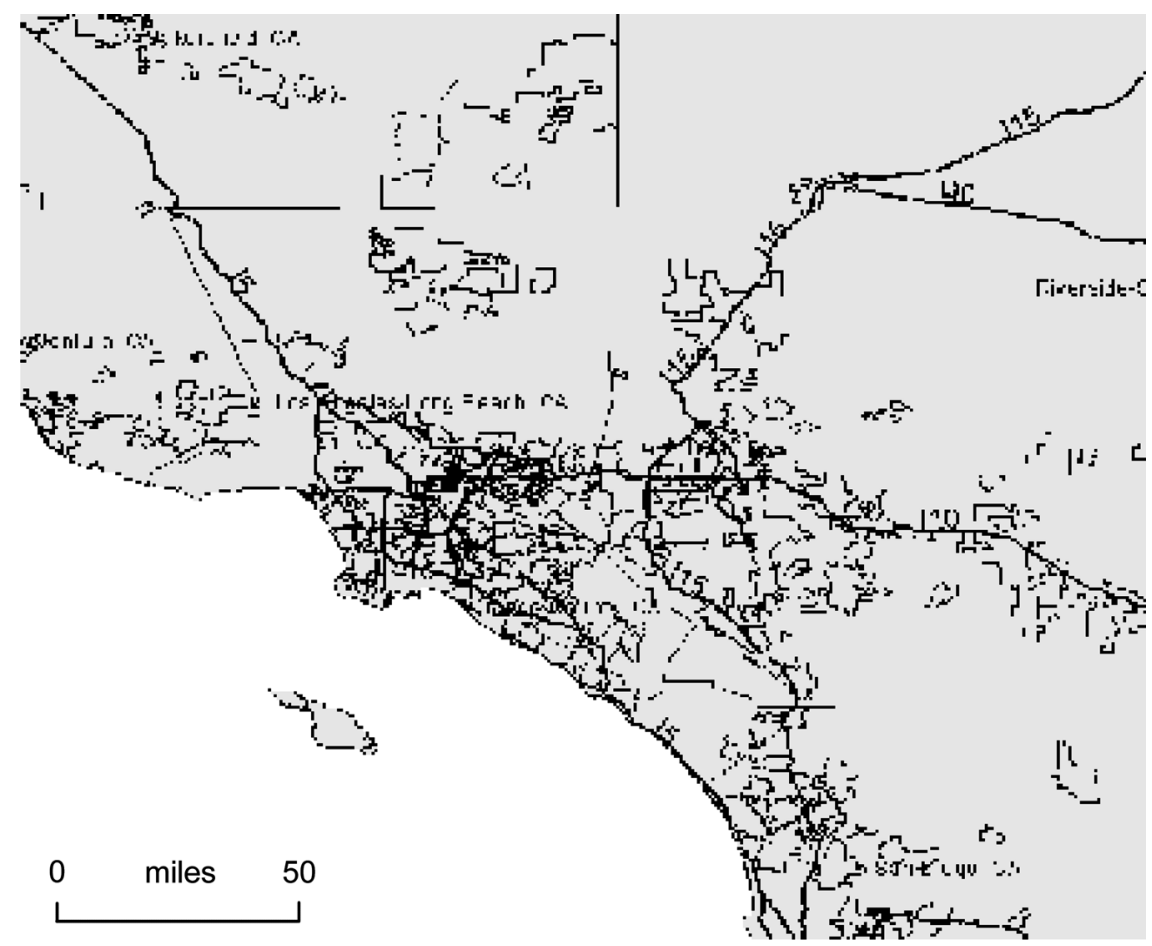

Figure 8. Net loss in the Hispanic population in the Los Angeles CMSA, 1990-2000. Key: 1 dot represents 100 people. 


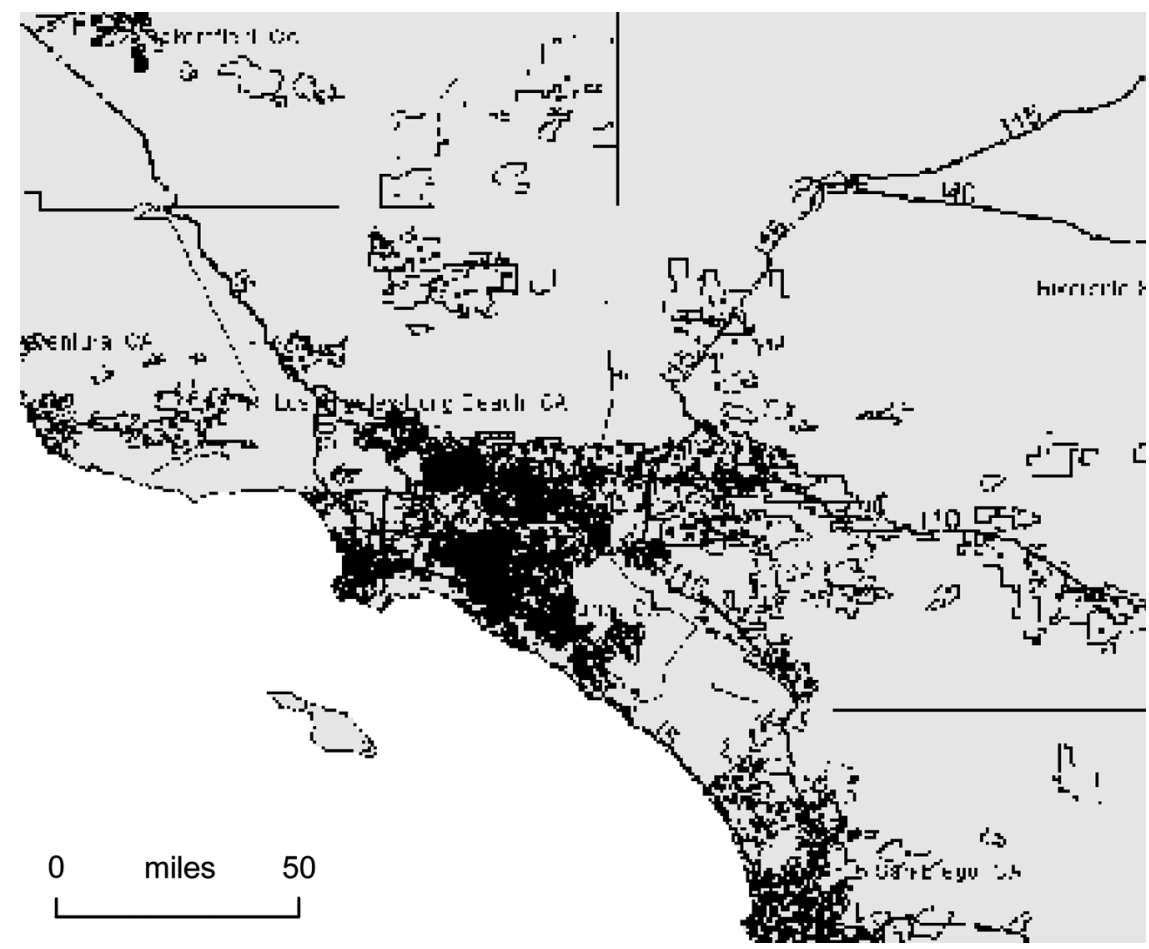

Figure 9. Net growth in the Asian population in the Los Angeles CMSA, 1990-2000. Key: 1 dot represents 100 people.

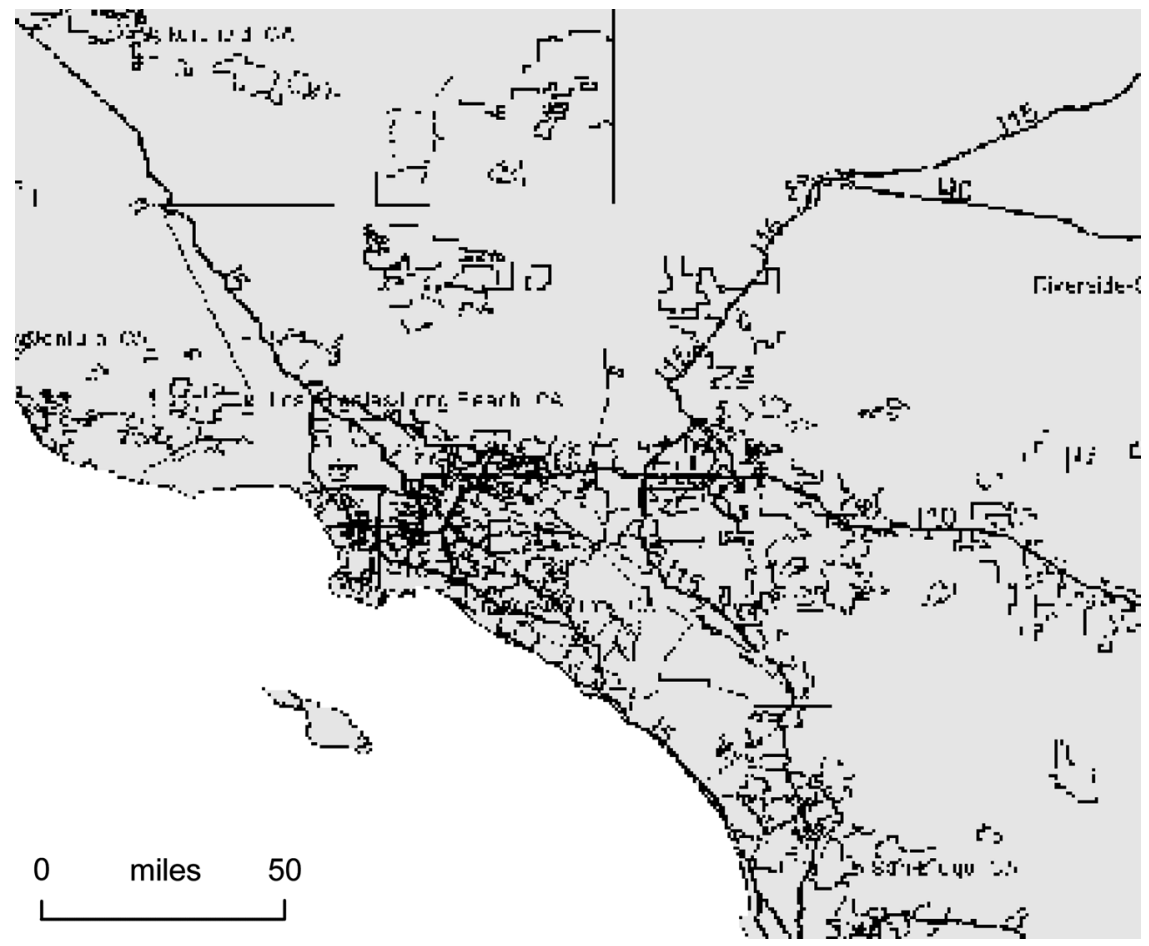

Figure 10. Net loss in the Asian population in the Los Angeles CMSA, 1990-2000. Key: 1 dot represents 100 people. 
Table 2. Measures of the dissimilarity between the 1990 resident population and the 1990-2000 net change in population by racial and ethnic groups for California census-designated places

\begin{tabular}{lccr}
\hline Racial/ethnic group & $\begin{array}{c}\text { Dissimilarity between net } \\
\text { population growth and } \\
\text { 1990 population }\end{array}$ & $\begin{array}{c}\text { Dissimilarity between net } \\
\text { population loss and 1990 } \\
\text { population }^{\mathrm{b}}\end{array}$ & \begin{tabular}{c} 
Chi-squared $^{\text {statistic }}$ \\
\hline Non-Hispanic White
\end{tabular} \\
Non-Hispanic Black & 81.9 & 39.6 & 20597774 \\
Non-Hispanic Asian & 62.3 & 61.2 & 5844452 \\
Hispanic & 39.4 & 95.3 & 2493543 \\
\hline
\end{tabular}

${ }^{a}$ For this measure, cities with absolute declines in the population of the relevant group have values set to zero. The figures give the dissimilarity index value between the 1990 population and the net growth in population for the relevant racial/ethnic group. These figures are interpreted as the percentage of net growth in the relevant population that would have to be redistributed in order to yield net increases in the population that are spatially proportional to the 1990 resident population.

${ }^{b}$ For this measure, cities with absolute increases in the population of the relevant group have values set to zero. The figures give the dissimilarity index value between the 1990 population and the net growth in population for the relevant racial/ethnic group. These figure are interpreted as the percentage of net decline in the relevant population that would have to be redistributed in order to yield net declines in the population that are spatially proportional to the 1990 resident population.

${ }^{\mathrm{c}}$ The chi-squared statistic for racial group $j$ is calculated based on the formula

$\Sigma_{i}\left(\text { change }_{i j}-\text { expected chang }_{i j}\right)^{2}$ /expected change $e_{i j}$

where, $i$ indexes places within California; change $i j$ gives the observed 1990-2000 net change in the resident population of members of group $j$ for city $i$, and expected change $e_{i j}$ is calculated by multiplying the proportion of the 1990 total population for group $j$ residing in city $i$ by the total change (1990-2000) in this population.

To measure proportional deviations from expectations, we divide by the absolute value of the expected change rather than the actual value. This does not matter for Blacks, Asians and Hispanics, since total net growth for these groups is positive over the decade. For Whites residing in incorporates places, however, net growth is negative. In all instances, the null hypothesis that population change was randomly distributed across the cities is rejected at the 1 percent level of confidence.

The chi-squared test statistics presented in the final column present a summary measure of the deviation from randomness of the net population change distribution for the four groups. The figures indicate the greatest deviations for Whites, followed by Blacks (in a far second), Hispanics and Asians.

The state-wide measures in Table 2 confirm the visual patterns presented for the Los Angeles CMSA in Figures 1-10. White population declines were drawn broadly from the cities in which they resided in 1990, while Black, Hispanic and Asian population declines were considerably more concentrated in a few cities. White population increases were quite concentrated spatially. Black population increases were also concentrated spatially, but in different cities and suburban parts of metropolitan areas. Asian and Hispanic population growth, in addition to being larger in overall magnitude, was dispersed across California's cities. We now turn to our empirical strategy for assessing the role of local land-use controls in shaping these patterns.

\section{Empirical Strategy and Data Descrip- tion}

The intercity shifts in population occurring during the 1990s follow quite discernable patterns and differ considerably by race and ethnicity. Local land-use policy may have affected these patterns since local officials control the numbers and types of permit issued for constructing residential buildings. To the extent that the distribution of household income and, by extension, housing demand differs across population groups, growth policy that favours relatively expens 
ive single-family detached housing may encourage population growth among racial/ethnic groups with higher average incomes. This may happen for two reasons. First, growth policy skewed towards more expensive housing units is more likely to exclude households with lower than average incomes. Given interracial/ethnic differences in the distributions of household income, any such exclusion is unlikely to be race-neutral. Secondly, a relatively exclusive housing policy may attract upper-income households actively seeking racially or ethnically homogeneous communities. To the extent that these households are drawn disproportionately from certain groups, land-use policy will affect the racial and ethnic composition of population change.

In this section, we describe the empirical strategy for assessing the influences of local land-use policy on the patterns of population change noted above. We first introduce two separate measures of the outcomes of local land-use policy, each based on the cumulative flow of residential building permits issued during the decade. These measures are key explanatory variables in models where the dependent variables are city-level population changes by race. Next, we present a strategy for assessing the exogeneity of these measures of land-use policy in the population change models. Specifically, we discuss two predetermined variables measuring the degree to which local land-use ordinances are either 'pro-growth' or 'exclusionary'. Subsequently, we use these exogenous variables as instruments in two-stage-least-squares (2SLS) models. We then present a description of our data.

\subsection{Characterising the Outcomes of Local Land-use Policy}

We construct two city-level policy measures based on new residential building permits issued during the 1990s. The first gauges the extent to which the number of single-family detached residential building permits issued within a given jurisdiction exceeds the expectation based on the proportion of these units within the city in 1990 and the overall growth in single-family detached units throughout the state. To be specific, define $\Delta$ Single $_{i}$ as the number of building permits issued between 1990 and 2000 for new single-family detached housing units in city $i$ and $\Delta$ Single as the sum of such permits over all cities in the state. Similarly, define Single $e_{i}$ as the number of single-family detached units within the city in 1990 and Singleas the total number of single-family detached units in the state for that year.

If new residential permits were distributed across cities in proportion to the distribution of the 1990 housing stock, then the expected number of single-family permits, $N_{i}$, issued by city $i$ is given by

$$
N_{i}=\Delta \text { Single }^{*} \frac{\text { Single }_{i}}{\text { Single }}
$$

We calculate the deviation from this proportionate allocation for each city. In the models estimated below, we express the deviation for each city as a proportion of the expectation for that city, or

$$
D_{i}=\frac{\Delta \text { Single }_{i}-N_{i}}{N_{i}}
$$

This proportionate deviation from expectations, $D_{i}$, is a key explanatory variable in the analysis presented below. We denote $D_{i}$ as the 'Deviation Index' for each city.

We relate this index to analogous measures of the extent to which population growth in city $i$ of members of group $j$ exceeds the expectation based on the intercity distribution of group $j$ in 1990 and the overall population growth of this group between 1990 and 2000. Specifically, let $P_{o p}$ be the 1990 population of group $j(j=$ White, Black, Hispanic, Asian) in city $i$ and $\mathrm{Pop}_{i}$ be the total 1990 population of this group in the state. Similarly, define $\triangle P o p_{j i}$ and $\triangle P o p_{i}$ as the corresponding 1990-2000 changes in the population of group $j$. The expected population change, $P_{j i}$, for group $j$ in city $i$ is given by

$$
P_{j i}=\Delta \operatorname{Pop}_{j} * \frac{\operatorname{Pop}_{j i}}{\operatorname{Pop}_{j}}
$$


while the proportionate deviation from expectations in population growth, $G_{j i}$, is merely

$$
G_{j i}=\frac{\Delta \operatorname{Pop}_{j i}-P_{j i}}{P_{j i}}
$$

We construct measures of proportionate deviations from expectations in population growth for each of the four racial/ethnic groups analysed graphically above and estimate separate models that regress the population change index on the housing permits index. $^{3}$

Higher values of the Deviation Index may arise for several reasons. First, if the local public sector uses its regulatory authority to alter the composition of newly constructed housing from its historical proportions and in a manner that favours single-family units, the stock of such housing will grow disproportionately. Alternatively, if the housing stock of a city increases at a rate that exceeds that of the state as a whole, the stock of singlefamily housing is likely to grow relatively faster, regardless of the degree of exclusivity of local housing policy. For example, differential growth across cities may be driven simply by differences in the extent of development in 1990. More developed, older cities may issue fewer permits than expected (as defined above) due to a lack of developable land or demand for new housing in older areas.

Both factors are positively related to the index of permit activity as defined in equation (2). The first source of variation is consistent with the use of local land-use policy to alter the composition of population growth. Hence, any correlation between the index and the population growth measure of a specific group attributable to this source of variation will reflect the impact of exclusionary land-use policy on the average residential decisions of members of a specific racial/ethnic group. The latter source of variation, however, is likely to be positively correlated with population growth of all groups, since an exceptionally high growth area is likely to experience growth in all sub-populations. Since both sources of variation are reflected in the single index, $D$, defined in equation
(2), it is impossible to disentangle the source responsible for any empirical relationship between the land-use policy measure and the population growth measure. ${ }^{4}$

Nonetheless, if population movements caused by high growth alone are similar across racial/ethnic groups, then the differences in the effect of the permits index across groups will reflect the impact of exclusionary controls. For example, if the effect of the Deviations Index is positive and significant for both Hispanics and Whites, but the effect on White population growth is larger, one might conclude that the impact of higher than expected growth in the stock of single-family housing encourages White population growth while discouraging Hispanic population growth (the effect of overall growth being net-out in the comparison). Below, we make such relative comparisons.

Our second measure of the extent to which local residential land-use policy is skewed towards single-family units is the simple ratio, $R_{i}$, of the number of single-family detached residential building permits issued in a given city during the decade to the total number, $T_{i}$, of new housing units authorised over the same period, or

$$
R_{i}=\frac{\Delta \text { Single }_{i}}{T_{i}}
$$

We denote $R$ as the 'Ratio Index' for each city. We relate this index to dependent variables measuring the proportion of population growth in a city accounted for by the change in the population of the four racial/ethnic groups analysed above. The Ratio Index has the advantage of scale-independence-i.e. the proportion of permits that are for singlefamily units does not depend in any way on overall city growth. Hence, a positive relationship between-for example, the proportion of net population growth in a city accounted for by Black population growth and the proportion of permits that are singlefamily should reflect the exclusivity of residential land use alone. ${ }^{5}$

Below, we present ordinary least-squares (OLS) regressions for the two types of model (defined by the alternatively constructed dependent variables and alternative measures of 
land-use policy defined in equations (2) and (5)) for each of the four racial and ethnic groups. We present estimates with and without controls for city-level characteristics as of the start of the decade.

\subsection{Using Growth-control Measures as In- struments for the Land-use Indices}

The OLS models outlined above make several implicit identifying assumptions. First, we assume that our building-permit indices, $D$ and $R$, are uncorrelated with unobserved factors affecting growth in the sub-populations of cities. Secondly, we assume that the regulatory outcomes (new permits issued) are not themselves caused by the population changes that we set out to model. In the models estimated below, we relax the first assumption by controlling for a wide variety of observable city-level variables intended to characterise the initial conditions of each city as of the start of the decade. Addressing the second assumption, however, is somewhat more difficult, since the potential simultaneity of population change and regulatory outcomes cannot be addressed merely by adding new control variables to the model specification.

To clarify this latter issue, suppose that Black households have strong preferences for residence in certain municipalities as well as strong preferences for single-family detached housing. Desirable municipalities will attract Black households who, in turn, will demand single-family detached units. If permits were simply issued in response to market demand, disproportionate growth in the number of single-family permits issued (or a higher proportion of all units accounted for by singlefamily permits) would merely reflect higher demand for such housing. Under these circumstances, a positive coefficient on the index $D$ or $R$ in a model of Black population change will reflect the effect of Black population change on the index and also the effect of the index on the population change.

Identifying the casual effect of the permits' indices on population changes requires identifying exogenous variation in the Deviations and Ratio Indexes through one or more instrumental variables. These variables must directly affect the process by which local governments issue permits, but their effect upon population is only indirect through their effects on the number of single-family permits. One set of potential instruments are the predetermined rules and regulations adopted by localities that constrain the supply of residential building permits. ${ }^{6}$

As noted above, regulation of growth-the expansion of housing by type and location, and permission to develop commercial and industrial property - is very much a prerogative of the local public sector in California. Regulations differ enormously in scope and detail, and enforcement practices vary as well. Fortunately, two comprehensive surveys of the regulatory environment at the city level were undertaken by Madelyn Glickfeld and Ned Levine and their associates, in 1988 and 1992. The 1992 survey was administered by the League of California Cities (LCC) and elicited a series of factual and attitudinal responses from the Planning Director or comparable official in each city. Official sponsorship by the LCC ensured a high response rate, approaching 90 per cent of the entities in California making these regulatory decisions. Details about the 1992 survey are reported in Glickfeld et al. (1999).

We use the results from this assessment to construct two instrumental variables intended to capture locally enacted restrictions on the supply of new housing and the composition of new housing. Our first measure is intended to capture the degree to which local land-use enactments in place as of the early 1990s were 'exclusionary' in the sense that they limited growth and skewed growth towards low-density and high-income housing. The LCC survey contains responses to a series of detailed questions about the existence and enforcement of specific restrictions on land use. Fifty different questions were asked about the existence for specific regulationsfor example, the maintenance of an urban growth boundary or the requirement of a referendum to approve density increases.

From the raw data, we selected a subset of 18 measures representing land-use restrictions that are likely to be exclusionary in the 
manner discussed above. ${ }^{8}$ Our measure of exclusivity reflects the incidence of these restrictive measures in a given municipality. The construction of the exclusivity measure is reported in Rosenthal (2000). A list of the variables used to construct it are presented in the Appendix (Table A1) together with theirfrequency distribution (Figure A1). We predict that the degree of exclusivity of local land-use policy should be negatively related to both the Deviation Index and the Ratio Index.

Our second measure of the regulatory environment is an index intended to capture the degree to which the municipality is hospitable to growth. This measure is based on local governments' responses to a series of questions about the encouragement of economic growth through the planning process or through explicit incentives. Nine of the most important measures encouraging or facilitating growth were identified and our 'progrowth' measure reflects the importance of these in a given municipality. ${ }^{9}$ Table A2 (see Appendix) presents the means for each measure while Figure A2 (Appendix) presents the frequency distribution of the final progrowth index. We predict that the pro-growth index should be positively correlated with the Deviations Index and negatively correlated with the Ratio Index.

Below, we present estimation results for the first-stage relationships between these measures of the 'exclusivity' and of the degree to which municipalities are 'pro-growth' and the two permit-based indices discussed above. We then use these two regulatory variables as instruments for the permit indices in 2SLS models of city-level population growth.

\subsection{Description of the Data}

The data for this project are drawn from four sources. First, place-level data on population by race and ethnicity are drawn from the 1990 Census Summary Tape Files 1 and preliminary counts from the 2000 Census Files 1. These data are used to calculate population changes by city and the population change indices discussed above. ${ }^{10}$
Secondly, we extracted initial data on the demographic and socioeconomic characteristics of each city from the 1990 Census Summary Tape Files 3 (for example, racial composition, median household income, poverty rates), as well as variables describing the housing stock and housing market conditions in 1990. These variables entered as controls in the models discussed below.

Thirdly, we use data on building permits recorded by the California Industry Research Board (CIRB). These data report the total number of residential building permits issued for each year between 1990 and 2000. In the estimation results below, we calculated the index based on the sum of permits issued during the decade. Building permits are reported separately for single-family detached and multiunit structures. CIRB data also include observations on the dollar value of office and commercial permits authorised during this period. We include these variables as controls in the population change regressions to adjust for population change that follows commercial development. The fourth data source is the LCC survey on local land-use regulation discussed in detail above.

\section{Empirical Results Using OLS}

We begin with a simple description of the bivariate relationships between our measures of population growth and our building permits measures of local housing policy. Figures 11-14 present scatter plots for each of the proportionate deviations from expectations in population growth measures against the Deviations Index in single-family detached units authorised over the decade. Superimposed on the scatter plots are the predicted regression lines from a regression of the population change on the Deviation Index, its square, and its cube. Figure 11 presents the data for non-Hispanic Whites and Figure 12 presents the results for African Americans. Figure 13 shows the scatter plot for Hispanics, while Figure 14 presents the results for Asians. Figures 15-18 present comparable scatter plots of the proportion of the net city-level population change against the Ratio Index. 


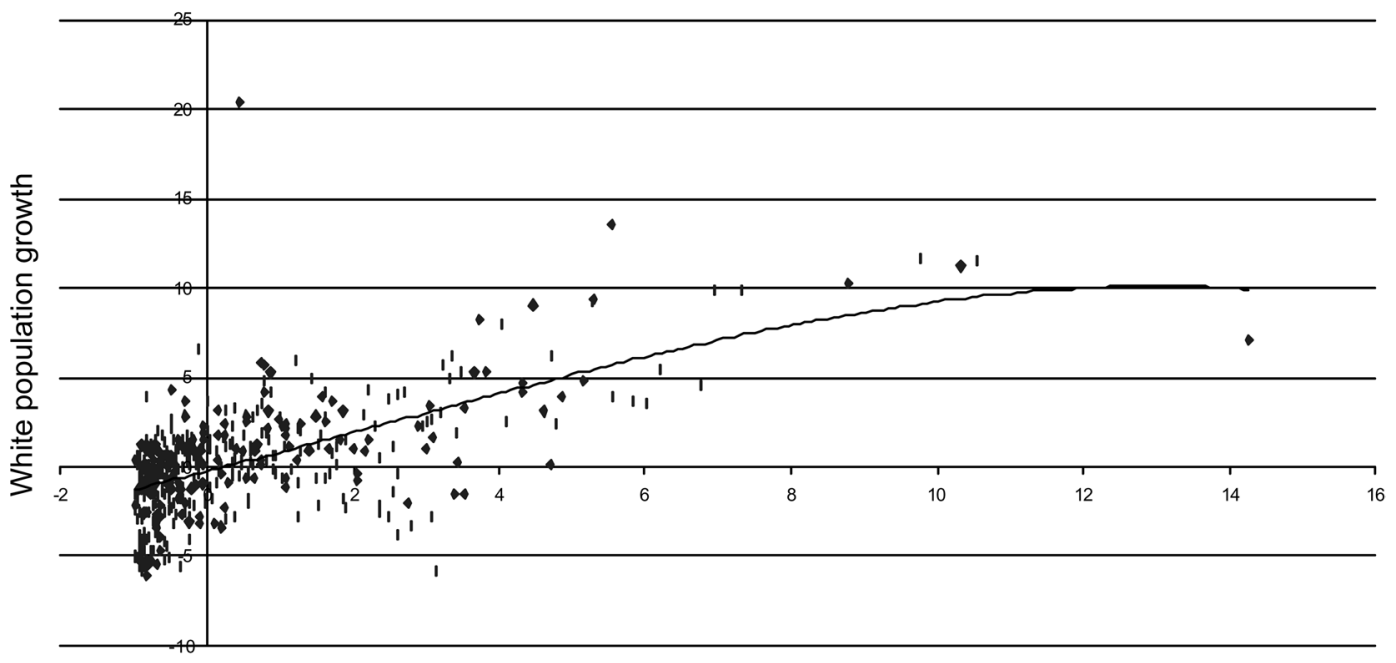

Single-family building permits

Figure 11. Proportional deviation from expectations in White population growth plotted against the Deviations Index.

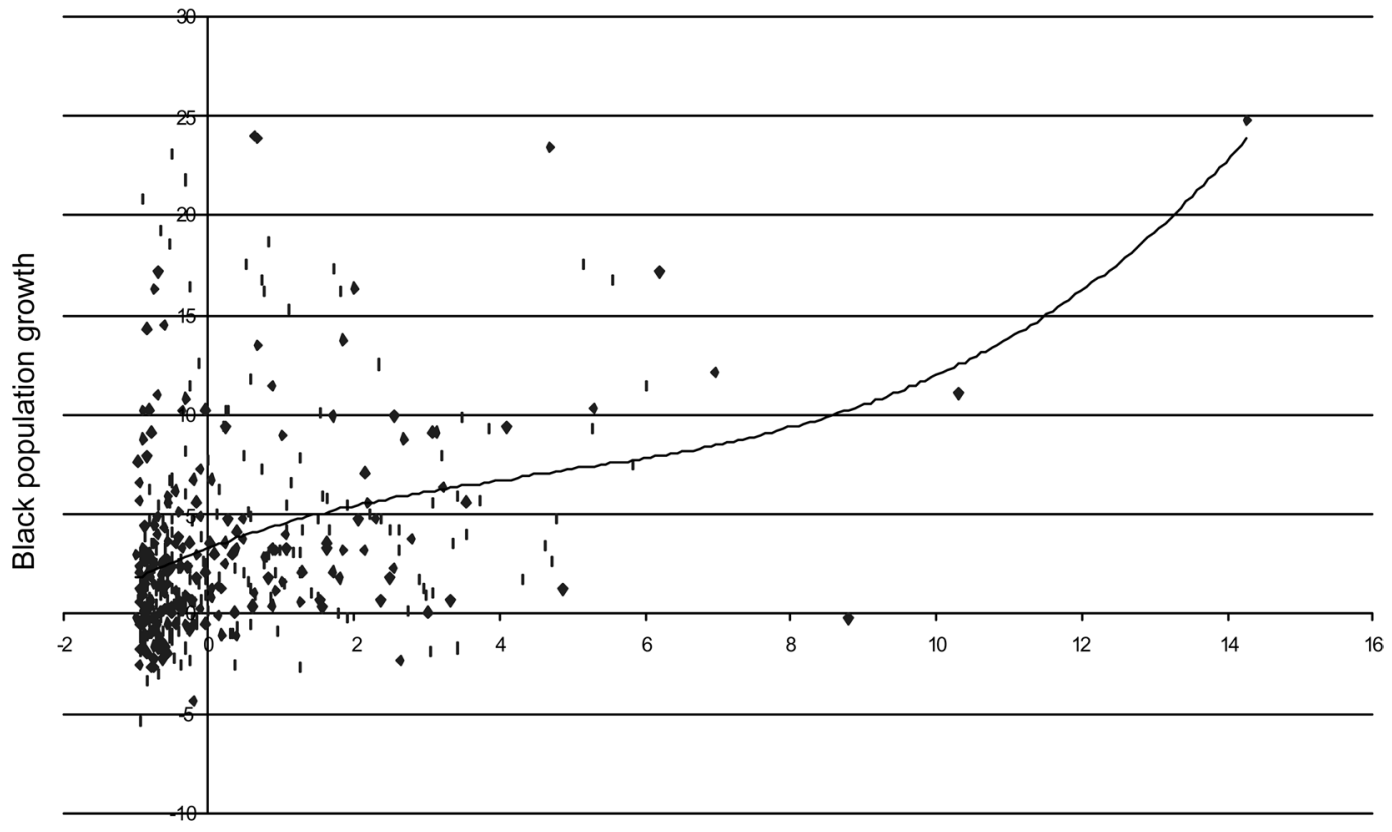

Single-family building permits

Figure 12. Proportional deviation from expectations in Black population growth plotted against the Deviations Index.

Figures 11 and 12 show relatively strong associations between the Deviation Index of local policy and the deviation from expectations in White and Black population growth. The data points are more tightly distributed around the regression line for Whites than for
Blacks. Figures 13 and 14 reveal considerably weaker relationships between the Deviations Index and net growth in the Hispanic and Asian populations. For all groups, the thirdorder regression equations are significant overall at the 1 per cent level of confidence. 


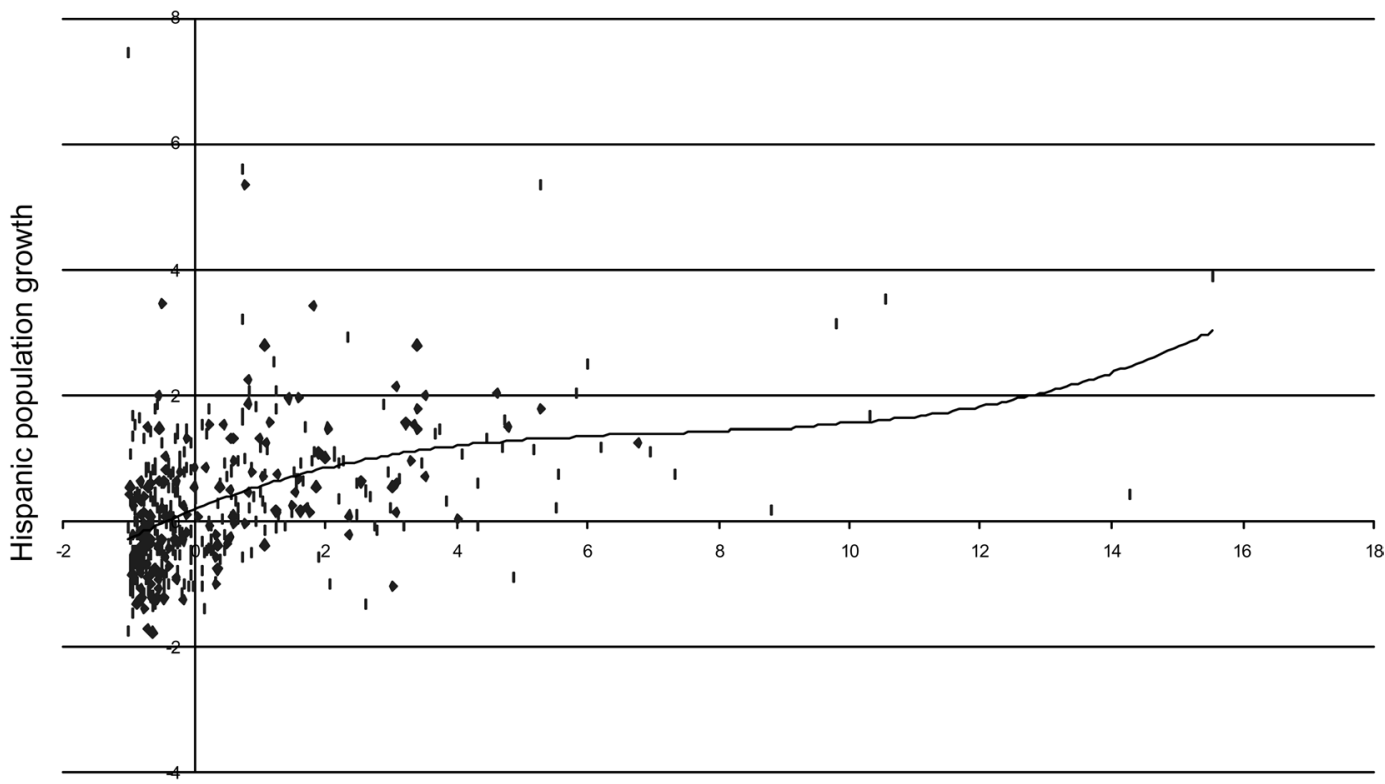

Single-family building permits

Figure 13. Proportional deviation from expectations in Hispanic population growth plotted against the Deviations Index.

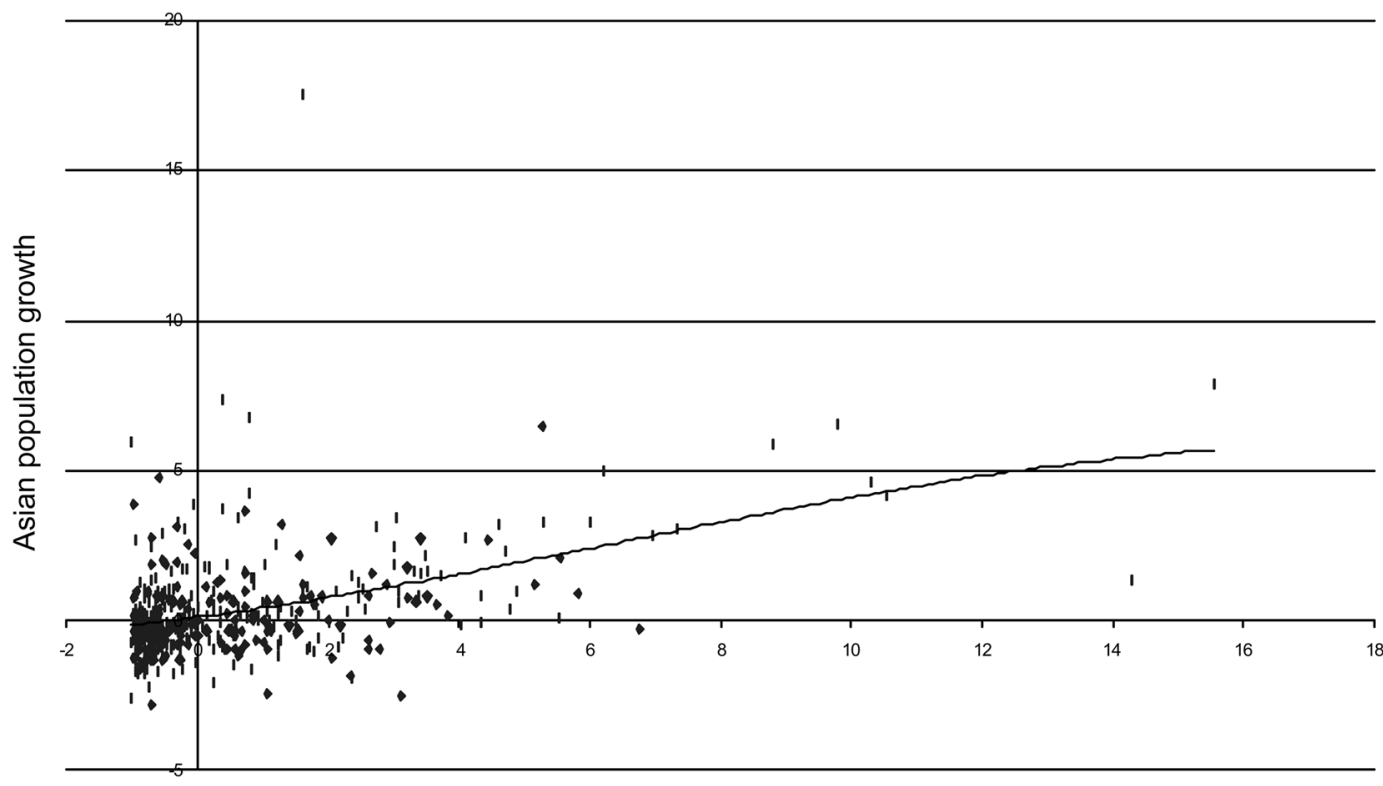

Single-family building permits

Figure 14. Proportional deviation from expectations in Asian population growth plotted against the Deviations Index.

Recall, a positive association between the housing stock that deviates from the average Deviations Index and net population growth- growth rate for cities in the state, or both. If may reflect either the exclusivity of local the effect of differential growth rates in the land-use policy, or the effect of growth in the housing stock is comparable across racial 
and ethnic groups, then the effect of exclusivity can be isolated by comparing the relative effects of the Deviations Index across racial and ethnic groups. These comparisons indicate that a growth policy skewed towards single-family housing is most likely to encourage growth in the non-Hispanic White and Black populations, followed by the Asian population, with the smallest effect (and perhaps the greatest exclusionary effect) on Hispanic population growth.

The results for the Ratio Index presented in Figures 15-18 indicate consistent patterns. Figure 15 demonstrates that the proportion of authorised units that are single-family detached is positively associated with the proportion of net population growth attributable to growth in the White population. Figure 16 shows no evidence of a relationship between the proportion of newly authorised units that are single-family and the proportion of population growth attributable to Black population growth. Figure 17 shows that the proportion of net population growth attributable to Hispanics is negatively associated with a proportion of newly authorised units that are single-family. The regression is significant overall at the one per cent level. Finally, Figure 18 reveals a smaller negative relationship between the proportion of new units single-family and the proportion of growth attributable to Asian population growth.

Note, that the Ratio Index is scale-independent-i.e. the proportion of permits that are single family does not depend on overall growth in the housing stock. Hence, the empirical relationships presented in Figures 1518 provide a more credible estimate of the potential exclusionary effect of local housing policy on net growth in each of the four population groups. With the exception of the results for African Americans, the empirical effects on White, Hispanic and Asian population growth for this latter index are consistent with the relative comparisons of the effects of the Deviations Index presented in Figures 11-14.

To be sure, the relationships in Figures 11-18 do not account for other city-level characteristics that are likely to be correlated with our measures of local public policy and that are also likely to determine net population changes for each of the four racial and ethnic groups. Tables A3 and A4 in the Appendix present comparisons that indicate substantial differences across cities. Table A3 presents comparisons of the average values for several city-level socioeconomic and housing market variables for cities with above-median and below-median population growth, as measured by the proportionate deviation from expectation in population growth. Separate comparisons are presented for cities with above- and below-median growth in each of the four population groups. Table A4 presents similar comparisons based on the alternative population growth measure (the proportion of net population growth accounted for by a specific group).

Table A3 indicates that cities with abovemedian growth in the non-Hispanic White population had smaller minority populations in 1990, had smaller 1990 populations, were more educated, less poor and less dense, had a younger housing stock, higher 1990 rents and higher median home values, and experienced less growth in new offices and stores. The comparisons of means for cities with above- and below-median growth in the Black population yield similar results with a few notable exceptions. There is little difference in the proportion Hispanic, mean education levels and the proportion poor and on public assistance between high- and lowBlack population growth cities. Blacks tended to move from high-rent to low-rent areas and from areas with high median home values to low median home values. In addition, the differences in the dollar value of new office and store developments between cities with above and below-median Black population growth are larger in absolute value than the differences observed for Whites. This pattern indicates that Black population growth occurs in areas with fairly low levels of new commercial activity, a pattern consistent with much of the research on the spatial mismatch hypothesis. ${ }^{11}$

In comparison with the growth patterns for 


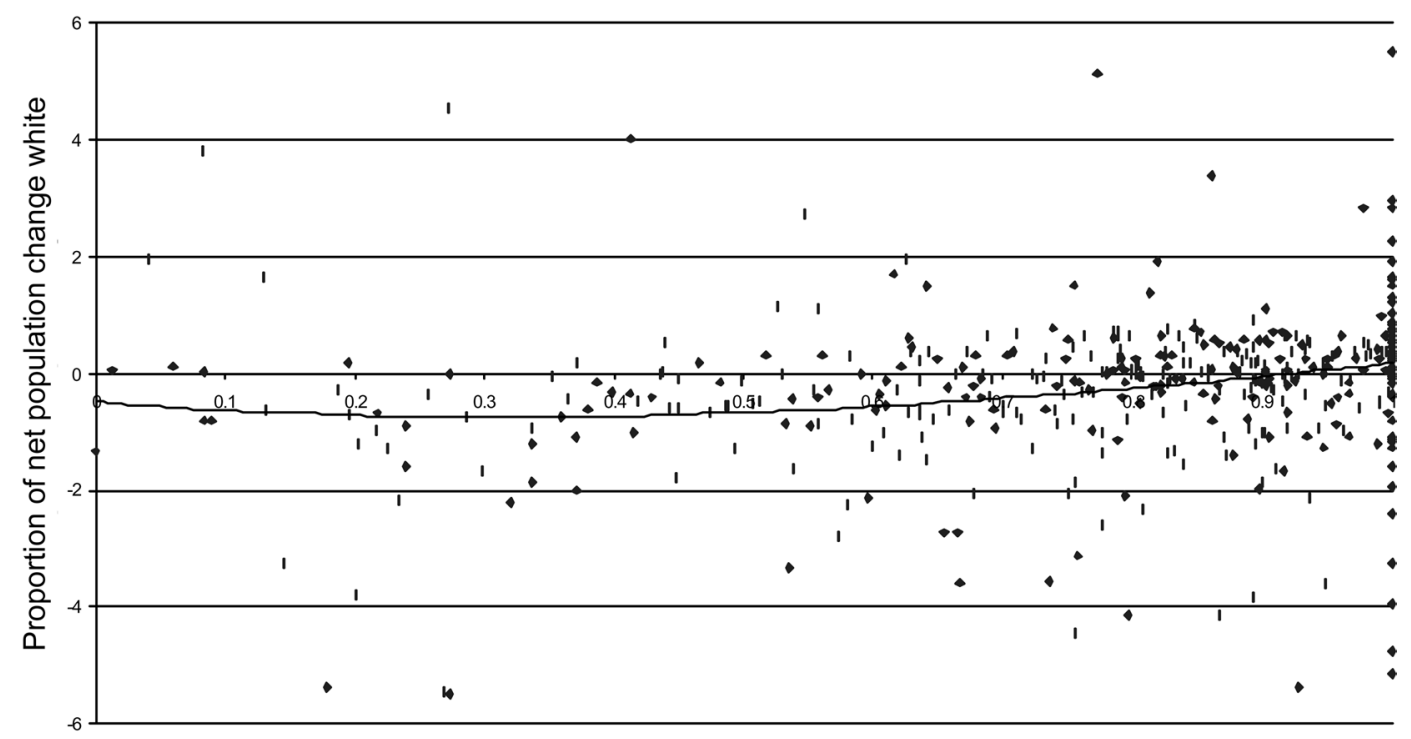

Proportion of permits single-family detached

Figure 15. Proportion of the net White population change plotted against the Proportions Index.

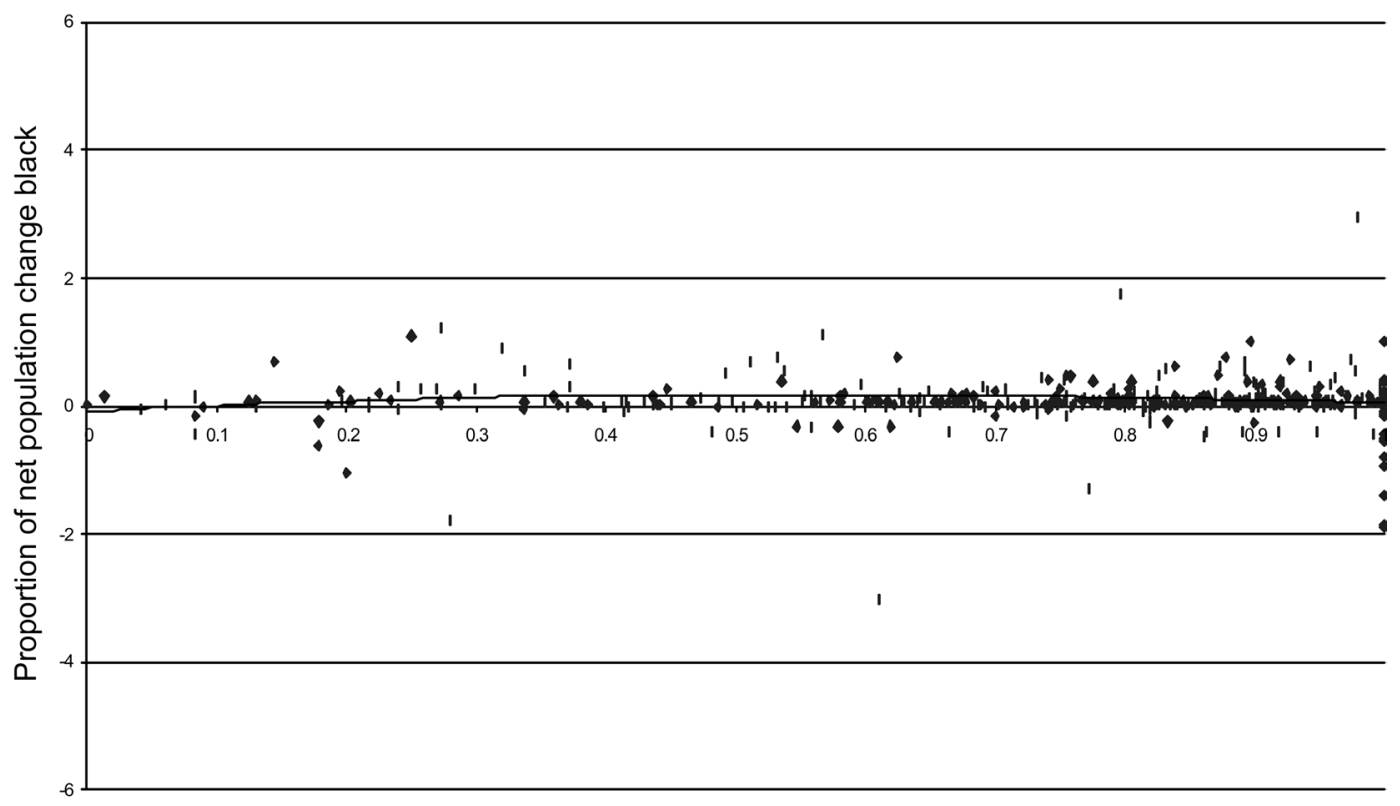

Proportion of permits single-family detached

Figure 16. Proportion of the net Black population change plotted against the Proportions Index.

Whites and Blacks, cities with above-median growth in the Hispanic population had proportionally larger minority populations in 1990, had larger overall populations, were relatively poor, had high proportions of the adult population that were high school dropouts, and lower proportions of the adult population with college degrees. For Asians, the differences between high- and lowgrowth cities are comparable with those for 


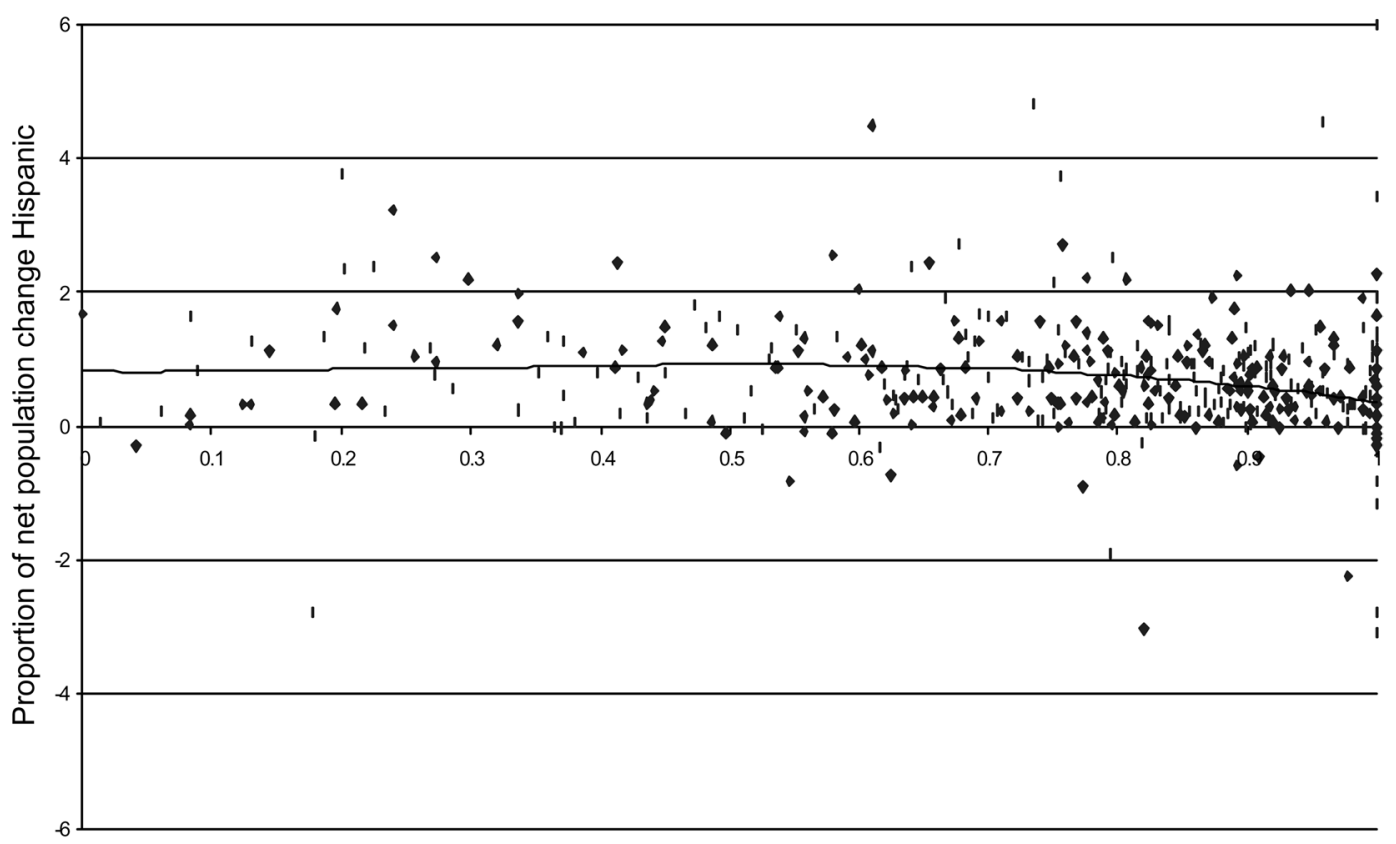

Proportion of permits single-family detached

Figure 17. Proportion of the net Hispanic population change plotted against the Proportions Index.

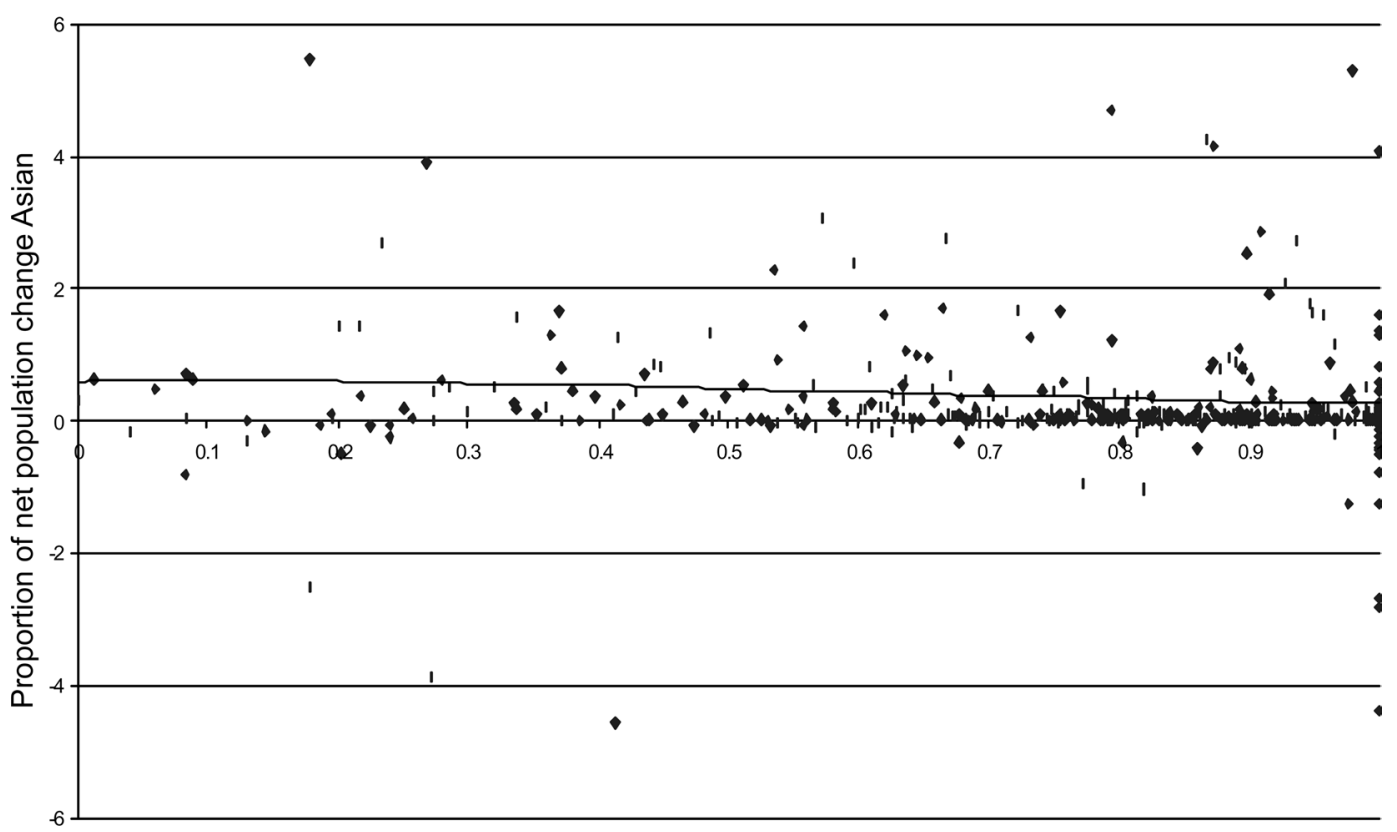

Proportion of permits single-family detached

Figure 18. Proportion of the net Asian population change plotted against the Proportions Index. 
Hispanics, although Asian population growth tends to be inversely related to the proportion of adults that are high school drop-outs, poverty and the proportion on public assistance. The comparisons using the alternative measure of population growth in Table A4 yield qualitatively similar results.

To assess whether these differences in city-level characteristics account for the patterns observed in Figures 11-18, the variables tabulated in the Appendix (Tables A3-A5) are used as controls in the regressions reported in Tables 3 and 4. Table 3 presents regression results where the dependent variable is the proportionate deviation from expectations in population growth and the key explanatory variable is the Deviations Index. ${ }^{12}$ For each racial and ethnic group, the table presents two regressions: the simple bivariate regression omitting all control variables and a regression including all of the variables in the Appendix tables. Table 4 presents comparable results where the dependent variable is the proportion of net population growth accounted for by members of specific racial or ethnic group and the key explanatory variable is the Ratio Index. ${ }^{13}$

The results reported in Table 3 indicate that the importance of the local policy (the Deviations Index) on population growth is not altered by controlling for observable citylevel characteristics. For the White (Black) population growth models, adding the control variables causes a slight decline in the coefficient on the permits index, from 1.066 to 0.957 ( 0.946 to 0.647$)$. In both instances, the permits effect is statistically significant at the 1 per cent level of confidence with and without the city-level explanatory variables. The estimated effect of the permits index on Hispanic population growth declines slightly when the city-level control variables are added to the specification while the marginal effect on Asian population growth is essentially unchanged. Again, all point estimates are statistically significant at the 1 per cent level of confidence.

The results in Table 4 using the alternative measure of population growth as the dependent variable and the Ratio Index as the key explanatory variable are less solid. For
Whites, adding the city-level control variable weakens the estimated effect of the index from 1.182 to 0.763 . The latter effect including the control variables is marginally significant. For the Black population growth models, the housing index is statistically insignificant in both regressions. The large significant negative effect of the housing permits index on Hispanic population growth is dampened considerably in the complete regression specification and is no longer statistically significant. Similarly, the impact of the housing permits index on Asian population growth is eliminated by the inclusion of the control variables.

\section{Empirical Results Using 2SLS}

The OLS results presented in the previous section suggest that development in the housing stock skewed towards single-family detached housing may encourage population growth among non-Hispanic Whites while discouraging population growth among Hispanics and Asians. The results for Blacks are mixed, with one housing index suggesting a positive effect of skewed development and the other indicating no relationship. As noted above, interpreting these results as causal is complicated by the potential endogeneity of the issuance of new permits for housing construction. Specifically, to the extent that certain populations demand certain types of housing, growth in some populations may 'cause' growth in the number of issued permits of one form or another.

In this section, we present estimation results where we use locally adopted supplyside constraints as instruments for our two measures of changes in the housing stock. Specifically, we use the index measuring the degree of 'exclusivity' and an index measuring the degree to which a municipality is 'pro-growth' as instruments for the two housing permits indices. We predict a priori that the degree to which a municipality is pro-growth should be positively associated with the Deviations Index and negatively related to the Ratio Index. The first prediction follows from the supposition that progrowth municipalities will encourage growth 


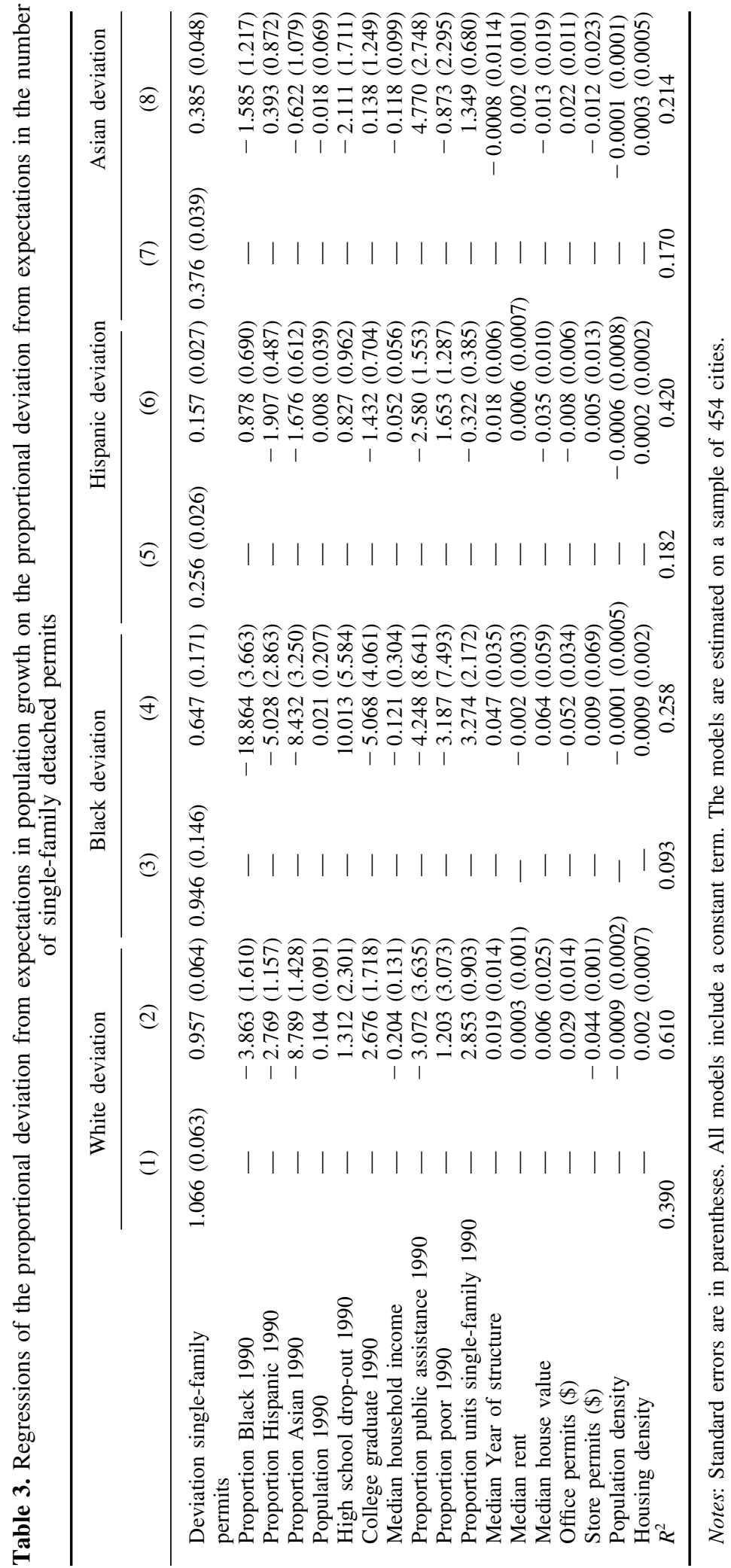




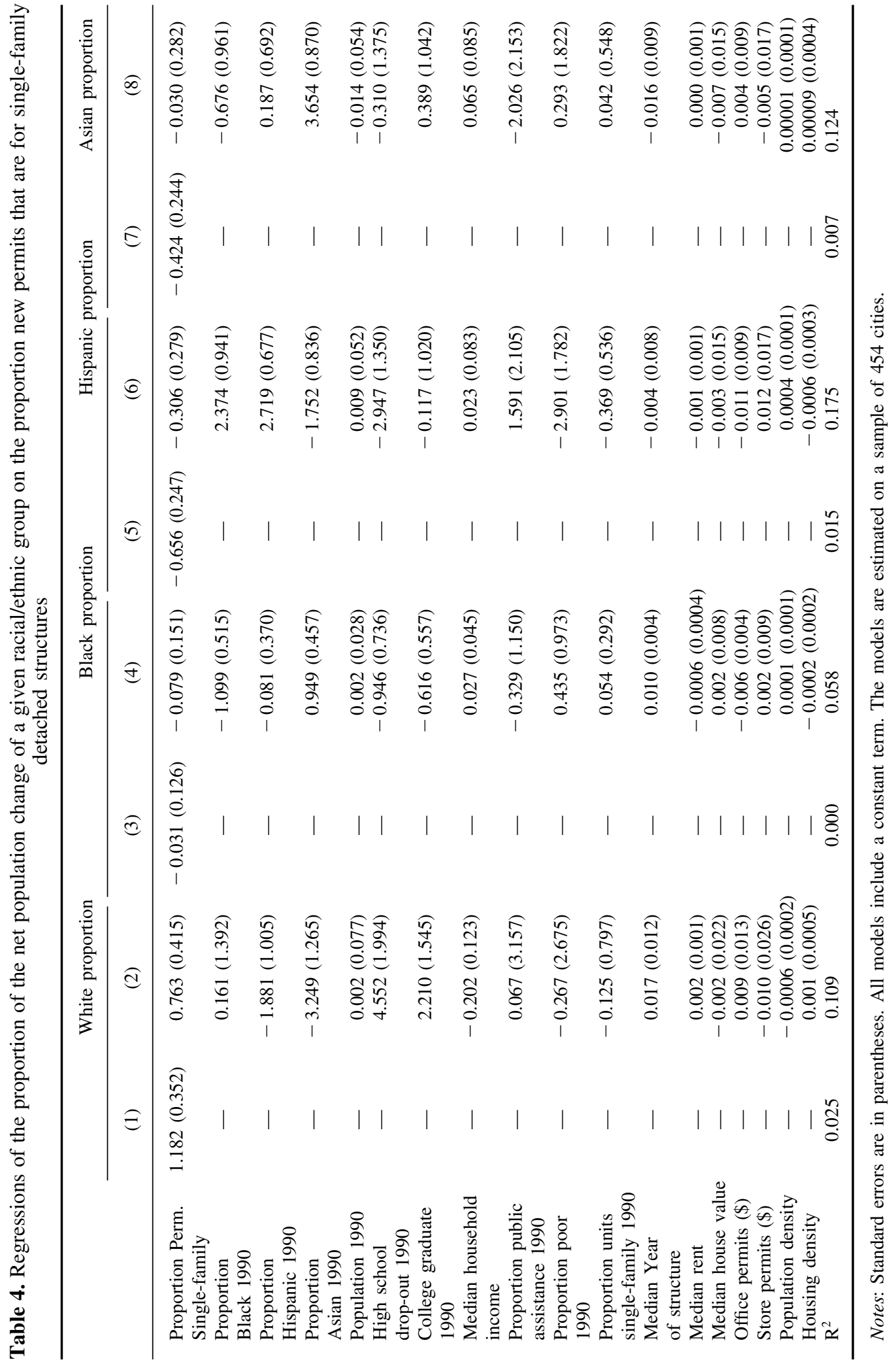


of all forms of the housing stock. The second prediction follows from the fact that population growth potential can be maximised with higher residential densities. We also predict that the exclusivity measure should be negatively related to both housing indices since exclusivity is associated both with controlling growth as well as the composition of growth.

Table 5 presents estimates of the firststage relationships between our housing indices and the two instrumental variables. For each of the housing indices, we present results from two first-stage regressions: a regression of the permits index on the pro-growth and exclusion indices with no other controls and a regression of the permits index on the two instrumental variables and all of the other covariates listed in Tables 3 and 4. To conserve space, we omit the coefficients on the control variables. The first two regressions in Table 5 present results where the dependent variable is the Deviations Index, while the third and fourth regressions provide results for the Proportions Index. The last row of each table presents the test-statistic and $p$-value from an $F$-test of the joint significance of the two instruments in each model.

There is a strong and significant positive effect of the pro-growth variables on the Deviations Index when no other controls are included in the specification. Adding the additional covariates, however, eliminates this effect. There is no measurable effect of the exclusion index in either equation. The firststage relationship between the instrumental variables and the Deviations Index evaporates once we add additional controls to the specification. The pro-growth index, however, exerts a negative and statistically significant effect on the Proportions Index in both models. The point estimate for the exclusion index is negative as predicted but insignificant in both models.

Table 6 presents a comparison of the OLS and 2SLS effect estimates of the two permits-based housing indices on the corresponding population change models. Here, we report the coefficients on the housing indices only. For all racial/ethnic groups, the 2SLS point estimates using the Deviations Index and omitting all other covariates are positive and statistically significant. Although the standard errors on the point estimates are large, the results confirm a significant positive effect in all instances. The ordering of effects, however, changes, with Blacks being most sensitive to excessive issuing of building permits followed by Hispanics, non-Hispanic Whites and Asians. The size of the standard errors precludes drawing strong inferences from these relative comparisons.

Comparisons of the OLS and 2SLS results when all other covariates are included in the model suggest that the latter estimates are unstable. Here, only the positive effect on Black population growth is marginally significant. These estimates, however, are based on an extremely weak first-stage regression and hence should be interpreted cautiously.

The 2SLS results for the models of the proportional contribution of each racial and ethnic group to net city-level population change are fairly imprecise. Despite the significant first-stage relationships in both models (see Table 5), the standard errors on the housing index effects are extremely large. While several of the OLS coefficients are significant at conventional levels of confidence, none of the 2SLS coefficients is statistically significant. ${ }^{14}$

\section{Conclusion}

The findings of this paper are several. First, within the context of a booming state economy with concurrent large changes in the internal racial and ethnic composition of the state population, we find quite clear patterns in population movements that suggest that local land-use policy is not race- or ethnicityneutral with respect to net changes in citylevel populations. We find clear evidence that the few cities experiencing growth in the non-Hispanic White population pursued residential development policies that were biased towards low-density residential development. 


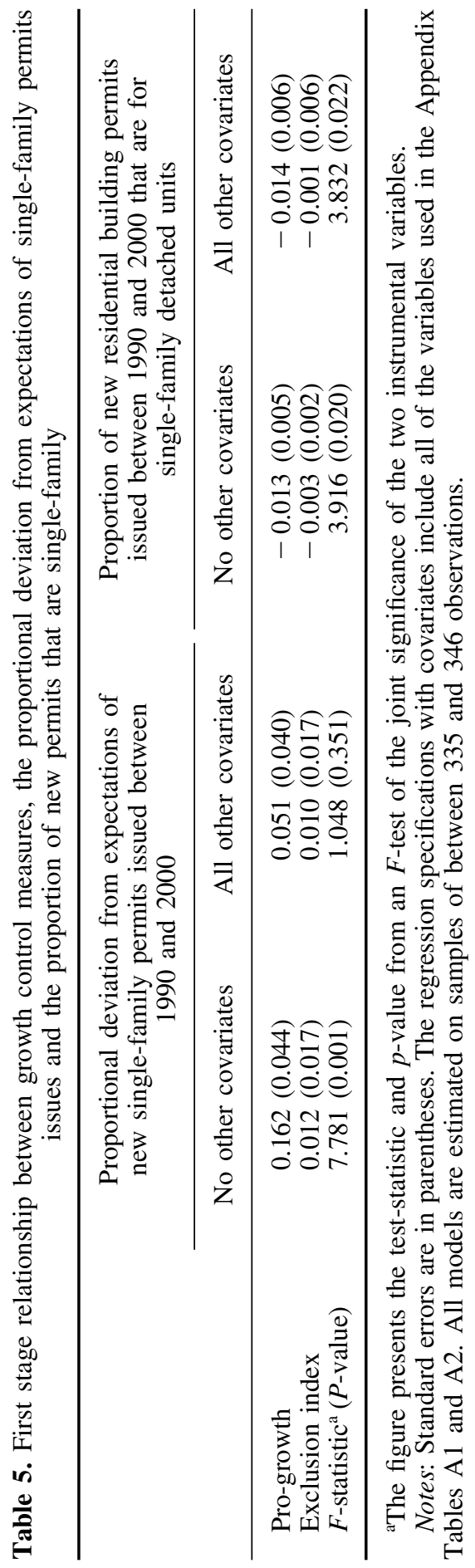




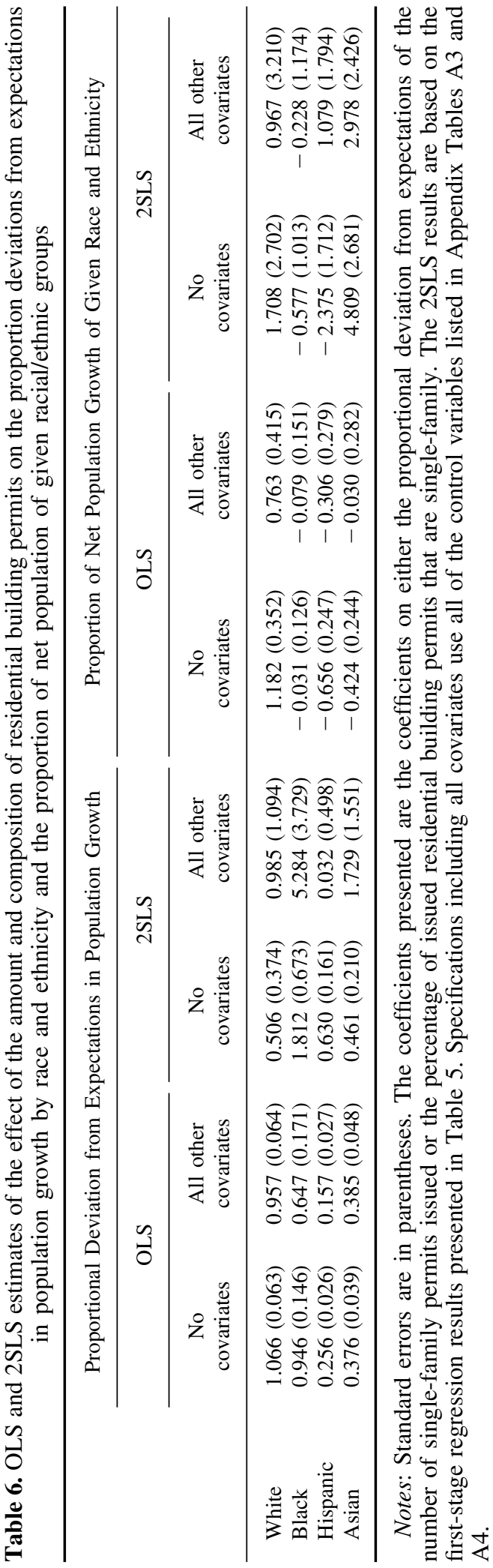


On the other hand, cities experiencing net losses in this population were those with growth in the housing stock biased towards higher-density development. Hispanic and Asian growth appears to be negatively affected by low-density residential development. The population movements of Black households appear to forge the middle path-i.e. positively influenced by growth in the singlefamily detached housing stock, but not to the degree of the impact on White population growth.

These findings indicate that local land-use policy significantly impacts the path and composition of population growth. Moreover, while the 2SLS results are not particularly strong, the significant effects in several of the models indicate that the permit process has real impacts on population growth rather than new permit following demand for new housing.

The results also indicate an interesting deviation of the experience of California during the 1990s from the geographical shifts in population movements occurring throughout the century in this and other US states. Previous research on exclusionary zoning practices have focused primarily on the impact of land-use policy on the ability of African American households to access exclusive communities. The patterns analysed here indicate that, while Black population growth is less responsive to policy geared towards lowdensity development than White, population movements among this group are clearly more positively affected by such policies than are the population changes of Hispanics and Asians, the two fastest-growing populations in California and in the nation as a whole. Hence, the focus of research should be widened to incorporate the potentially disparate impacts of land-use policy on these additional racial and ethnic groups.

\section{Notes}

1. For evidence on the effect of local zoning on housing prices, see Courant (1976), Dowall and Landis (1982), Katz and Rosen (1987), Malpezzi (1996), and Schwartz and Zorn (1988). For evidence of the effect of growth regulations on overall population growth and the changes in non-White population, see Levine (1999).

2. Maps of population changes for the other three major metropolitan areas in the state, the San Diego Metropolitan Statistical Area (MSA), the San Francisco-Oakland-San Jose CMSA and the Sacramento MSA, yield portraits of population dynamics that are qualitatively similar to those observed in the LA basin. To economise on space, we present detailed maps for the most central CMSA only.

3. For Whites, the expected value of the population change for each city is negative, since the White population declined for the state overall. To ensure that a negative deviation corresponds to a population decline that was greater than expectations and that a positive deviation corresponds to a decline that was smaller than expected, we divide the deviation by the absolute value of the expected change rather than by the actual value. This is not necessary for the measures of change for the other three groups since these populations increased overall.

4. For example, a positive relationship between the deviation from expectation in the growth in the Hispanic population and the deviation from expectations in the number of permits issued might reflect the sum of a large positive effect due to disproportionately high growth in the housing stock and a smaller negative effect of the exclusionary nature of land-use policy (with the positive effect of disproportionate growth dominating).

5. To be sure, while single-family detached housing is more expensive on average than housing units in multi-unit structures, there are several counter-examples of high-income, exclusive neighbourhoods where the housing stock and recent flow of permits favour high-end condominiums and rental units. Since our two measures of land-use policy are based on single-family detached permits alone, our indices will mischaracterise such neighbourhoods. Such mischaracterisations will add measurement error to our indices and hence will bias OLS coefficients towards zero.

6. Zoning constraints on land supply have been shown empirically to reduce housing supply and increase prices (Butler, 1981; Henderson, 1985; Pogodzinski and Sass, 1991). There are also several studies that establish that land-use regulation in California increases the price of existing housing while reducing the value of developable land (for example, Dowall and Landis, 1982; Elliot, 1981; Schwartz and Zorn, 1988). 
7. A comparison of the 1988 and 1992 surveys is found in Levine (1999). The 1998 survey is reported in Glickfeld and Levine (1992).

8. The full list of questions pertaining to exclusionary enactments include residential phased development, sub-divisions, floor area ratio restrictions, building permit restrictions, population restrictions, provisions for adequate services, redesignation of land for open space or agricultural use, density reduction, requirements for referenda on density increases, requirements for legislative supermajority for density increases, adequate services provisions for commercial development, square footage caps for commercial and industrial development, rezoning commercial and industrial development to lower intensity, height reduction provisions, provisions for growth management, urban growth boundaries and other development restrictions. The full list is documented in the Appendix (Table A1). This table also indicates the proportion of California cities that adopted each enactment. Figure A1 in the Appendix presents the relative frequency distribution for our constructed instrument.

9. These measures include provisions for altering the general plan for growth accommodation, recent 'up-zoning' for higher densities, propensity to engage in regulatory fast-tracking, the provision of financial growth incentives, reduction of exaction fees, the provision of direct infrastructure subsidies, the participation of redevelopment agencies, active economic recruiting and other growth encouragement.

10. Since the methods used to collect information on race in the 2000 Census differ from those for 1990, a word on population definitions is necessary. In the most recent census, respondents were permitted to identify more than one race in describing themselves. In California, fewer than 5 per cent of respondents did so. We employ the following definitions to define mutually exclusive categories. All non-Hispanic Whites who identify themselves by one racial category only are coded as White. We define the African American population as all individuals who identify themselves as African American by choosing a single racial descriptor or by choosing several. We apply the similar rule to define the 2000 Asian population. (In California, approximately 10 percent of those who identified themselves as African American chose at least one additional racial category. Approximately 11 per cent of those who identified themselves as Asian chose at least one additional racial category.) The Hispanic population is technically an ethnic rather than a racial group and is drawn from all races. The Hispanic population is measured identically in both census years. If most of the bi- and multi-racial individuals represent those choosing White and Black and those choosing White and Asian, this coding scheme will render the population described in the two censuses comparable.

11. See Ihlanfeldt and Sjoquist (1998) for an extensive review of this literature.

12. Since the scatter plots presented in Figures 11-14 indicate that several of the models may be sensitive to the observation where the deviation index exceeds 14, we dropped this observation. Omitting controls, one cannot reject a linear specification in all but the Hispanic regression. With covariates, the square and cube of the deviation index are jointly insignificant in all models. Hence, in Table 3, we present the results only for models that are linear in the deviations index.

13. In all models presented in Table 4, one cannot reject the hypothesis of linearity in the ratio index.

14. We also analysed the simple reduced-form relationships between our measures of population growth and the pro-growth and exclusivity instruments. These additional results are presented in the Appendix (Table A5). These results indicate that, while the degree of exclusivity is positively and significantly related to White population growth in excess of expectations, the degree to which a city is pro-growth is positively and significantly related to excessive growth in the other three population groups. For our population growth variables, measuring the proportion of total growth attributable to each group, there are no significant reduced-form relationships between our instruments and the outcomes variables.

\section{References}

BUTLER, H.-J. (1981) equilibrium of a residential city, attributes of housing and land-use zoning, Urban Studies, 18(1), pp. 23-39.

Courant, P. (1976) On the effect of fiscal zoning on land and housing values, Journal of Urban Economics, 3(1), pp. 88-94.

Dowall, D. E. AND LANDIS, J. D. (1981) land use controls and housing costs: an examination of San Francisco Bay Area communities, AREUEA Journal, 10, pp. 67-93.

ELLIOT, M. (1981) The impact of growth control regulations on housing prices in California, AREUEA Journal, 9, pp. 115-133.

Glickfeld, M. and LEVINE, N. (1992) Regional Growth, Local Reaction: The Enactment and 
Effects of Local Growth Control and Management Measures in California. Cambridge, MA: Lincoln Institute of Land Policy.

GLICKFELD, M. et al. (1999)

HENDERSON, J. V. (1985) The impact of zoning policies which regulate housing quality, Journal of Urban Economics, 13, pp. 302-312.

IhlanfeldT, K. R. and SJoquist, D. (1998) The spatial mismatch hypothesis: a review of recent studies and their implications for welfare reform, Housing Policy Debate, 9(4), pp. 842892.

KatZ, L. F. and Rosen, K. T. (1987) Interjurisdictional effects of growth controls on housing prices, Journal of Law and Economics, 30(1), pp. 149-160.

LEVINE, N. (1999) The effects of local growth controls on regional housing production and population redistribution in California, Urban Studies, 36(12), pp. 2047-2068.
MALPEZZI, S. (1996) Housing prices, externalities, and regulation in U.S. metropolitan areas, Journal of Housing Research, 7(2), pp. 209-241.

PogodZINSKI, J. M. and SASS, T. R. (1991) Measuring the effects of municipal zoning regulations: a survey, Urban Studies, 28(4), pp. 597-621.

Rosenthal, L. A. (2000) Long division: California's land use reform policy and the pursuit of residential integration. Unpublished $\mathrm{PhD}$ thesis, Goldman School of Public Policy.

Schwartz, S. I. and Zorn, P. M. (1988) A critique of quasi experimental and statistical controls for measuring program effects: application to urban growth control, Journal of Policy Analysis and Management, 7(3), pp. 491-505.

THEIL, H. (1972) Statistical Decomposition Analysis. Amsterdam: Elsevier.

\section{Appendix}

Table A1. Measures of 'exclusivity' in local land-use regulations, 1992

\begin{tabular}{lcc}
\hline Subject of regulation & $\begin{array}{c}\text { Percentage of } \\
\text { adoption by cities }\end{array}$ & $\begin{array}{c}\text { Earliest year of } \\
\text { adoption }\end{array}$ \\
\hline Residential & 14 & 1969 \\
Identification of phased development areas & 5 & 1970 \\
Restriction on sub-divisions & 46 & 1950 \\
Floor area ratio restriction & 14 & 1977 \\
Restriction on building permits & 10 & 1975 \\
Restriction on population growth & 42 & 1956 \\
Adequate services requirement & 11 & 1962 \\
Redesignation of residential land to open space & 38 & 1974 \\
or agricultural use & 6 & 1977 \\
Density reduction via general plan or rezoning & 3 & 1986 \\
Referendum requirement for density increases & & \\
Legislative supermajority requirement for & & 1964 \\
density increases & 36 & 1980 \\
Commercial & 6 & 1980 \\
Adequate services requirement & 5 & 1960 \\
Square footage cap (commercial) & 20 & 1954 \\
Square footage cap (industrial) & 28 & \\
Rezoning to less intense use & & 1973 \\
Reduction in allowable height & & 1965 \\
Growth control & 18 & 1976 \\
Adoption of growth Management element for general plan & 17 & \\
Adoption of urban growth boundary & 16 & \\
Other development restrictions & & \\
\hline
\end{tabular}

Source: California State Association of Counties and League of California Cities, Survey on Local Growth Management and Control Measures (1992). 


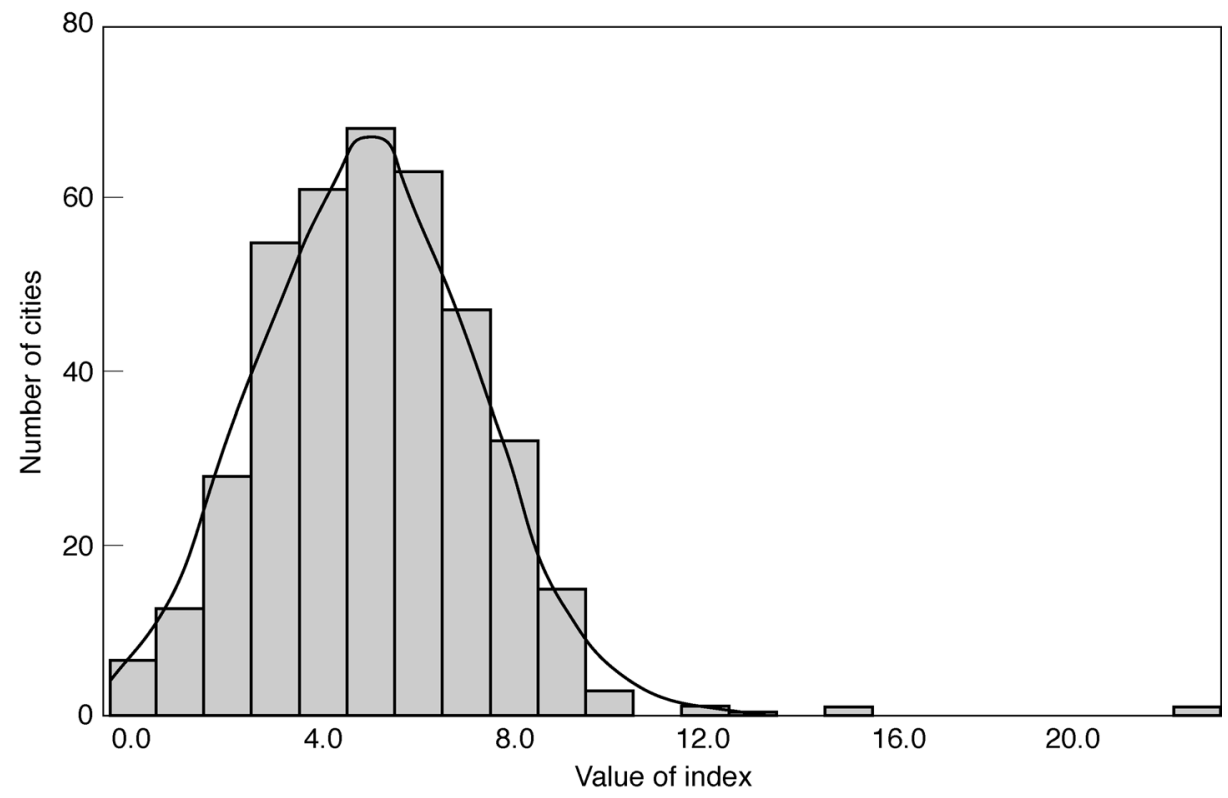

Figure A1. Frequency distribution of measure of 'exclusivity'.

Note: computed from variables reported in Table A1, using methodology described in Rosenthal (2000).

Table A2. Measures of 'hospitality' to growth in local land-use regulation, 1992

\begin{tabular}{lc}
\hline Subject of regulation & Average importance $^{\mathrm{a}}$ \\
\hline Encouragement via planning & \\
General plan capacity and accommodation & 3.5 \\
Rezoning to higher density & 2.9 \\
& \\
Encouragement via Incentives & 3.6 \\
Regulatory fast tracking & 2.6 \\
Financial incentives & 2.7 \\
Reduced exactions & 2.3 \\
Direct infrastructure subsidies & 3.2 \\
Redevelopment incentives & 3.4 \\
Economic development policy & 3.0 \\
Other growth encouragement & \\
\hline
\end{tabular}

aAverage measure of 'importance' of policy, rated 1 ('not at all important') to 5 ('very important').

Source: California State Association of Counties and League of California Cities, Survey on Local Growth Management and Control Measures (1992). 


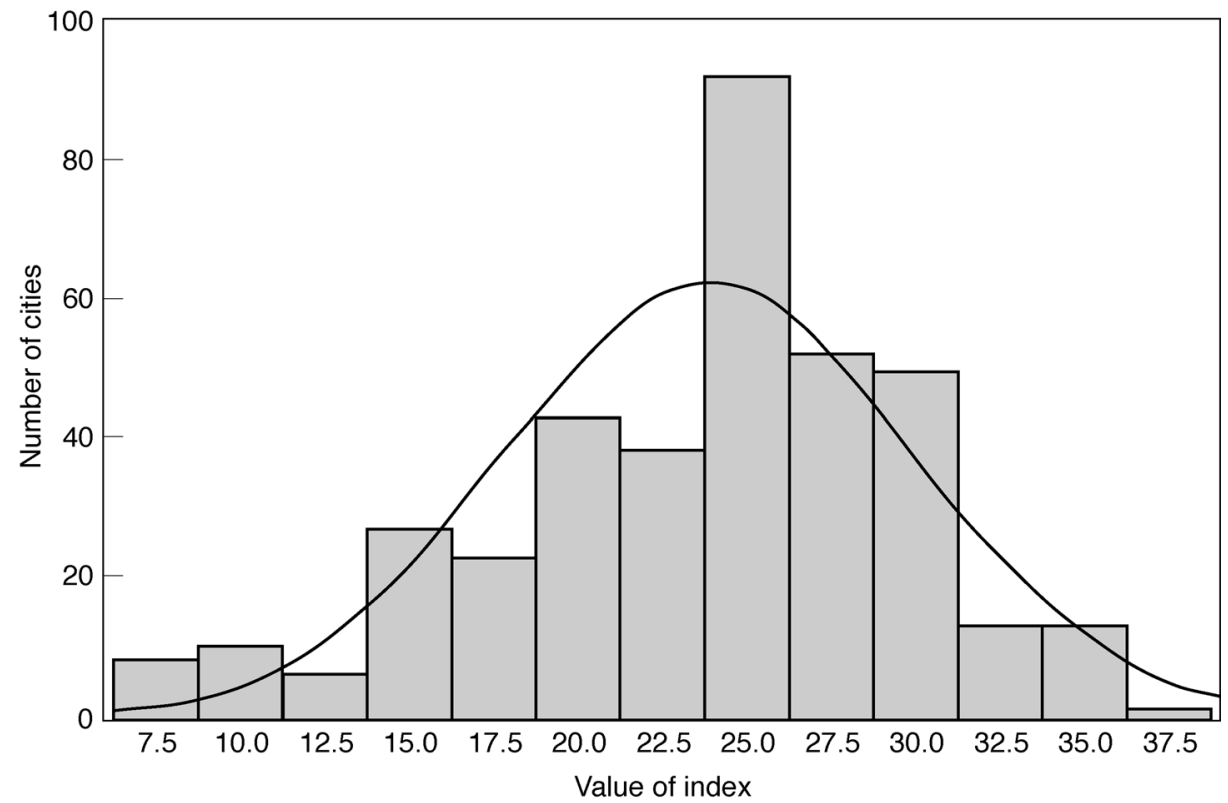

Figure A2. Frequency distribution of measure of 'hospitality' to growth. Note: computed from variables reported in Table A1, using methodology described in Rosenthal (2000). 
LAND-USE CONTROLS AND DEMOGRAPHIC OUTCOMES

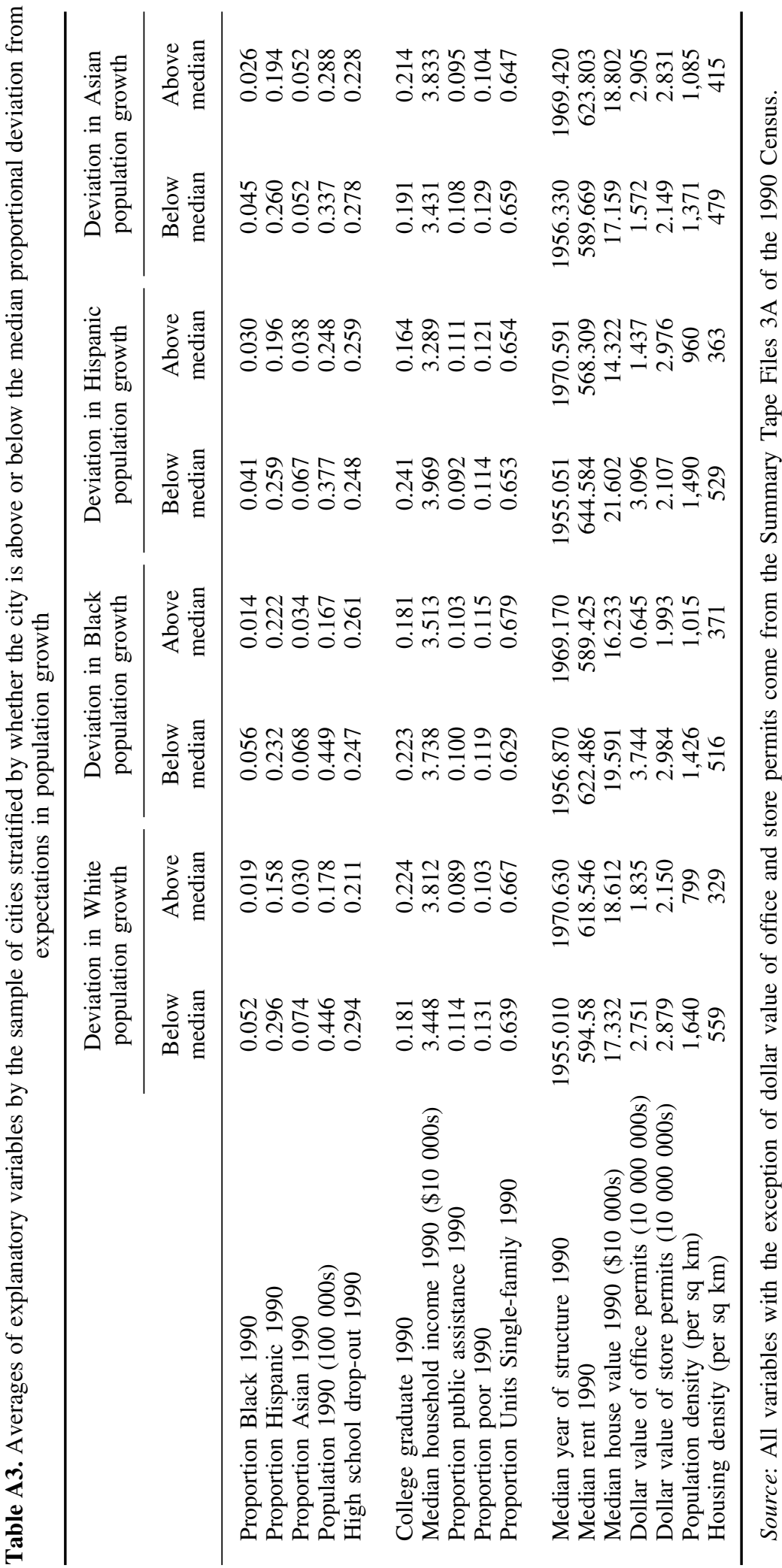




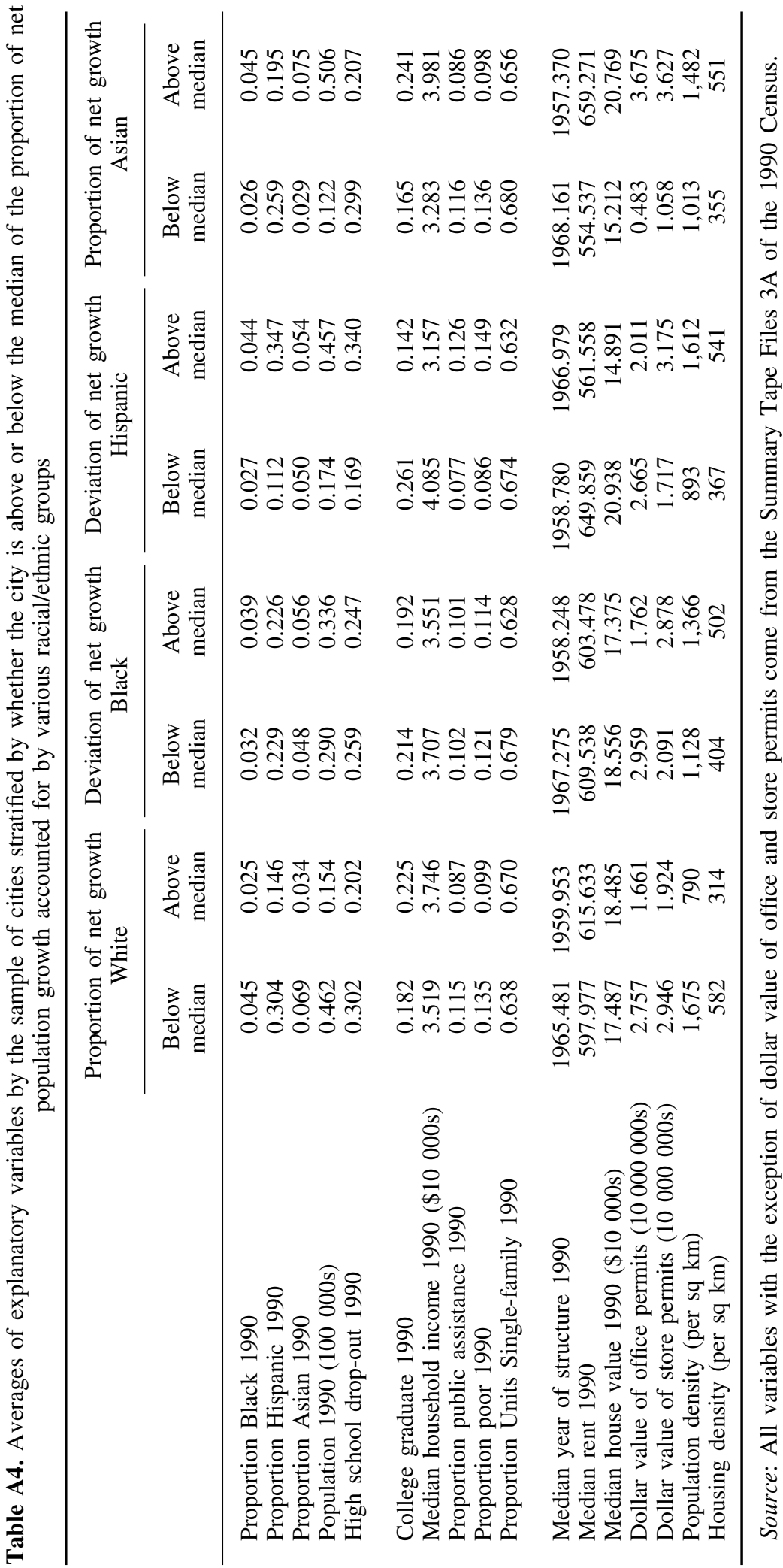




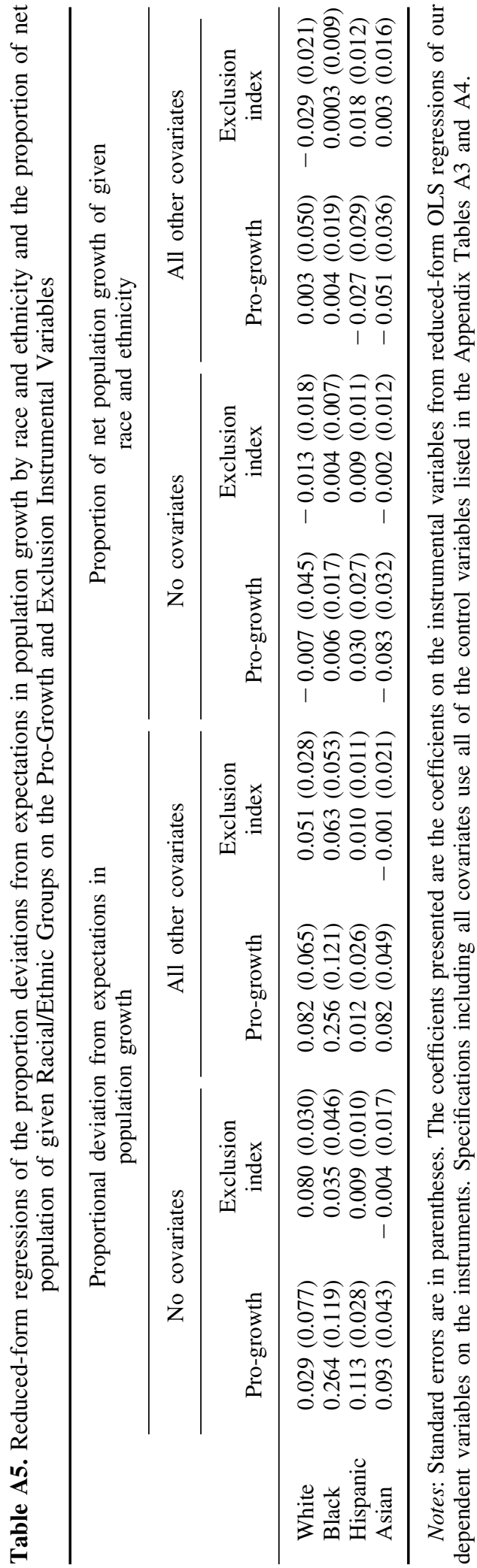




\section{Author Query Sheet}

\begin{tabular}{|l|l|}
\hline \multicolumn{2}{|c|}{ Manuscript Information } \\
\hline $\begin{array}{l}\text { Journal } \\
\text { Acronym }\end{array}$ & URS \\
\hline $\begin{array}{l}\text { Volume and } \\
\text { issue }\end{array}$ & $41(2)$ \\
\hline Author name & Quigley et al. \\
\hline $\begin{array}{l}\text { Manuscript } \\
\text { No. (if } \\
\text { applicable) }\end{array}$ & P9 \\
\hline
\end{tabular}

AUTHOR: The following queries have arisen during the editing of your manuscript. Please answer the queries by marking necessary corrections at the appropriate positions on the PROOFS. Do not answer the queries on the query sheet itself. Please also return a copy of the query sheet with your corrected proofs.

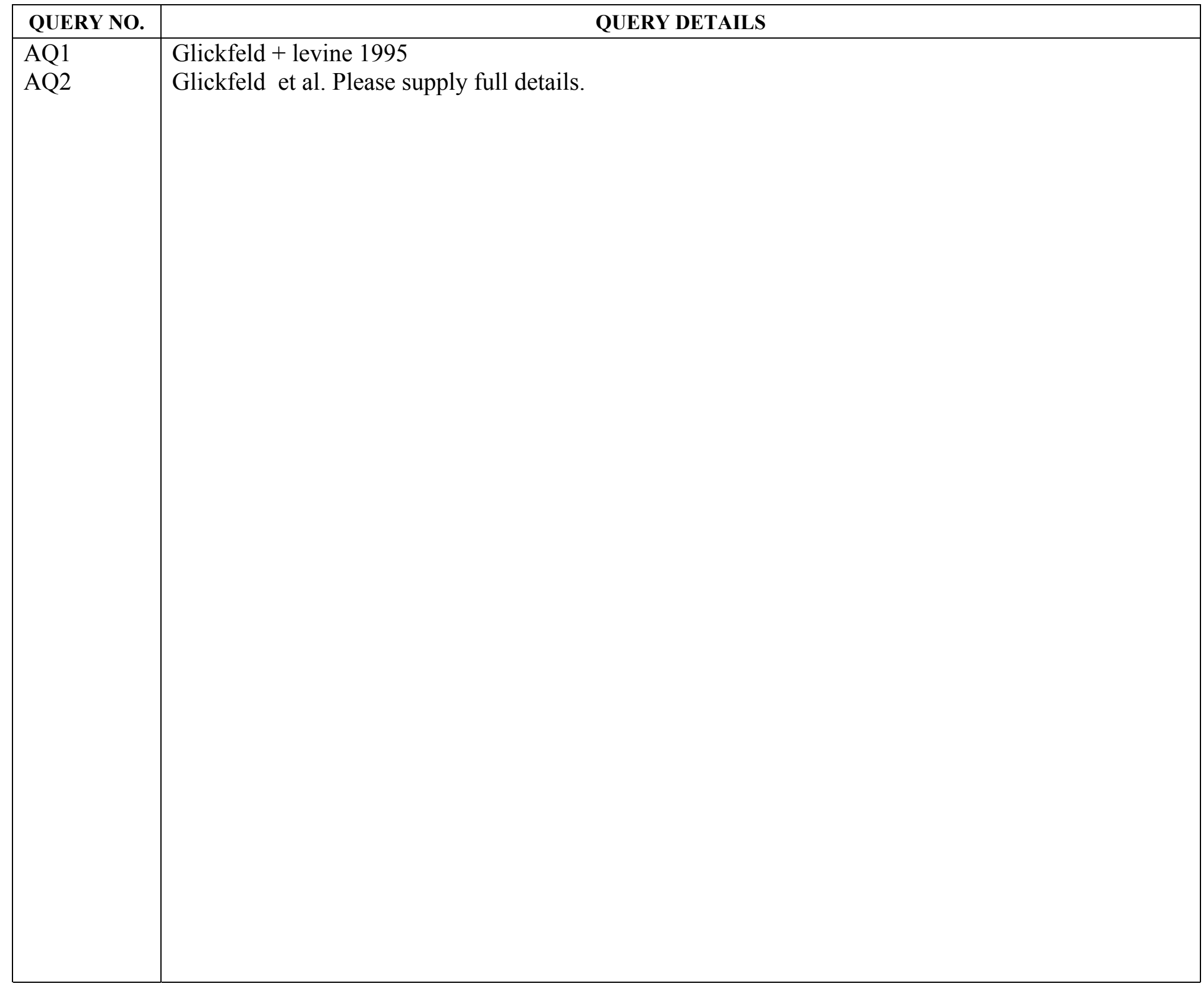

